\title{
INJECTED MATRIX STIMULATES MYOGENESIS AND REGENERATION OF MOUSE SKELETAL MUSCLE AFTER ISCHAEMIC INJURY
}

D. Kuraitis ${ }^{1,2,3}$, D. Ebadi ${ }^{4}$, P. Zhang ${ }^{1}$, E. Rizzuto ${ }^{3}$, B. Vulesevic ${ }^{1,2}$, D.T. Padavan ${ }^{1}$, A. Al Madhoun ${ }^{4}$, K.A. McEwan ${ }^{1,5}$, T. Sofrenovic ${ }^{1,2}$, K. Nicholson ${ }^{1}$, S.C. Whitman ${ }^{6}$, T.G. Mesana ${ }^{1}$, I.S. Skerjanc ${ }^{4}$, A. Musarò ${ }^{3}$, M. Ruel ${ }^{1,2}$, and E.J. Suuronen ${ }^{1,2, *}$

${ }^{1}$ Division of Cardiac Surgery, University of Ottawa Heart Institute, 40 Ruskin Street, Ottawa K1Y 4W7, Canada ${ }^{2}$ Department of Cellular and Molecular Medicine, University of Ottawa, 451 Smyth Road, Ottawa K1H 8M5, Canada

${ }^{3}$ Institute Pasteur Cenci-Bolognetti, DAHFMO-Unit of Histology and Medical Embryology, IIM,

University of Rome La Sapienza, Via Scarpa 14, 00181, Rome, Italy

${ }^{4}$ Department of Biochemistry, Microbiology and Immunology, University of Ottawa, 451 Smyth Road, Ottawa K1H 8M5, Canada

${ }^{5}$ Faculty of Engineering, University of Ottawa, 161 Louis Pasteur Drive, Ottawa K1N 6N5, Canada ${ }^{6}$ Vascular Biology Laboratory, University of Ottawa Heart Institute, 40 Ruskin Street, Ottawa K1Y 4W7, Canada

\begin{abstract}
Biomaterial-guided regeneration represents a novel approach for the treatment of myopathies. Revascularisation and the intramuscular extracellular matrix are important factors in stimulating myogenesis and regenerating muscle damaged by ischaemia. In this study, we used an injectable collagen matrix, enhanced with sialyl Lewis ${ }^{\mathrm{X}}\left(\mathrm{sLe}^{\mathrm{X}}\right)$, to guide skeletal muscle differentiation and regeneration. The elastic properties of collagen and $\mathrm{sLe}^{\mathrm{X}}$-collagen matrices were similar to those of skeletal muscle, and culture of pluripotent mESCs on the matrices promoted their differentiation into myocyte-like cells expressing Pax3, MHC3, myogenin and Myf5. The regenerative properties of matrices were evaluated in ischaemic mouse hind-limbs. Treatment with the $\mathrm{sLe}^{\mathrm{x}}$-matrix augmented the production of myogenic-mediated factors insulin-like growth factor (IGF)-1, and IGF binding protein-2 and -5 after 3 days. This was followed by muscle regeneration, including a greater number of regenerating myofibres and increased transcription of Six1, M-cadherin, myogenin and Myf5 after 10 days. Simultaneously, the sLe ${ }^{\mathrm{X}}$-matrix promoted increased mobilisation and engraftment of bone marrow-derived progenitor cells, the development of larger arterioles and the restoration of tissue perfusion. Both matrix treatments tended to reduce maximal forces of ischaemic solei muscles, but $\mathrm{sLe}^{\mathrm{X}}$-matrix lessened this loss of force and also prevented muscle fatigue. Only sLe ${ }^{\mathrm{X}}$-matrix treatment improved mobility of mice on a treadmill. Together, these results suggest a novel approach for regenerative myogenesis, whereby treatment only with a matrix, which possesses an inherent ability to guide myogenic differentiation of pluripotent stem cells, can enhance the endogenous vascular and myogenic regeneration of skeletal muscle, thus holding promise for future clinical use.
\end{abstract}

Keywords: Hydrogel; injectable; muscle; neovascularisation; regenerative medicine; tissue-material interactions.
*Address for correspondence:

E.J. Suuronen

Division of Cardiac Surgery,

University of Ottawa Heart Institute

40 Ruskin Street, Ottawa, ON K1Y 4W7, Canada

Telephone Number: 613-798-5555, ext. 19087

FAX Number: 613-761-5367

E-mail: esuuronen@ottawaheart.ca

\section{Introduction}

The capacity of adult tissues to regenerate in response to injury stimuli represents an important homeostatic process. Nevertheless, the complete regenerative program in cases of aging, extended injury, peripheral artery disease or pathological conditions is severely affected and it is precluded by fibrotic tissue formation and consequent functional impairment. It is likely that the restricted tissue repair program under pathological conditions is due to either progressive loss of stem cell populations or to missing signals that limit the damaged tissues to efficiently activate a regenerative program (Carosio et al., 2011). Despite major advances in medicine, current therapies do not yet allow for muscle regeneration to take place when needed. Attempts at stem cell therapy for these diseases have demonstrated experimental success; for instance, the transplantation of cultured circulating angiogenic cells (CACs) can restore perfusion in ischaemic hind-limbs (Kuraitis et al., 2011a); embryonic stem cells can improve function and prolong life in a spinal muscular atrophy model (Corti et al., 2010); and, improvement of motor function following mesenchymal stem cell transplantation was demonstrated in a model of DMD (Li et al., 2011). Despite such promise, no optimal therapy has yet emerged, and the need for strategies to regenerate muscle remains considerable.

The limitations of stem cell therapy are partially attributed to the poor engraftment and persistence of transplanted cells (Suuronen et al., 2008). To address this, materials are being tested as stem cell delivery vehicles for the regeneration of muscle; in particular, components of the body's extracellular matrices may be advantageous for therapeutic application because cells already have a pre- 
disposition for recognising them (reviewed in Kuraitis et al. (2012)). Other technical challenges of stem cell therapy may include: potential requirement for co-administration of immunosuppressant drugs, time required for preparation of cells for transplantation, and unavailability of autologous cells. Therefore, as an alternative, an acellular approach to tissue regeneration has the potential to circumvent the risks and demands of these limitations. Recent studies have focused on the ability of implantable materials to augment tissue regeneration after ischaemic damage by the release of stem cell-activating growth factors (Borselli et al., 2010; Saif et al., 2010; Kuraitis et al., 2012). Another strategy, one that does not rely on having to control the release of growth factors, may be to provide the tissue with a healthy cell-supportive environment by implanting a material that can mediate and augment the body's natural responses.

In designing such a biomaterial, it may be vital to consider the importance of vasculature and the extracellular matrix in the muscle regeneration process. Specifically, revascularisation and the provision of an adequate blood supply represent major limiting parameters for a successful therapeutic approach at regenerating muscle damaged by ischaemia (Ko et al., 2007; Grounds, 2008). Regenerative myogenesis has been characterised by increased transcription of the myogenic regulatory factors (MRFs) MyoD, Myf5 and myogenin (Sabourin and Rudnicki, 2000), and may be augmented by the activation and maturation of local myocyte progenitors, termed satellite cells, often identified by Pax 7 expression (Parise et al., 2006). In addition, appropriate adaptive changes in the intramuscular extracellular matrix can enhance the potential of muscle to recover and/or regenerate from damage (Kovanen, 2002). Notably, type I collagen is the predominant component of the skeletal muscle's extracellular matrix (San Antonio and Iozzo, 2006), and has been used for muscle cell differentiation in myoblast cell culture and in grafts (Kroehne et al., 2008). Collectively, these findings suggest that a collagen-based material that can promote blood vessel growth may be an ideal candidate treatment for promoting skeletal muscle regeneration.

We previously reported on a type I collagen-derived matrix that contained the oligosaccharide sialyl Lewis ${ }^{\mathrm{X}}$ $\left(\mathrm{sLe}^{\mathrm{X}}\right.$ ), a ligand for the receptor L-selectin (Suuronen et al., 2009). L-selectin, a receptor for $\mathrm{sLe}^{\mathrm{x}}$, is expressed on the surface membrane of circulating angiogenic cells (CACs), and has a role in regulating their homing and adhesion (Biancone et al., 2004). When applied in a rat model of muscle ischaemia, the $\mathrm{sLe}^{\mathrm{X}}$-matrix increased

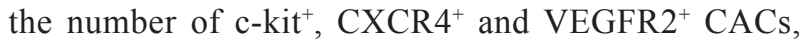
augmented blood vessel regeneration and restored perfusion, while not eliciting a foreign body or harmful immune response (Suuronen et al., 2009). Given the importance of vasculature and the extracellular matrix in muscle regeneration, and since the $\mathrm{SLe}^{\mathrm{x}}$-matrix can promote neovascularisation and its composition is based on type I collagen, we hypothesised that it may possess the ability to stimulate regenerative myogenesis.

In this study, we characterised the mechanical properties of the $\mathrm{sLe}^{\mathrm{x}}$-matrix (which may be contributing factors towards its regenerative effects), and its ability to promote differentiation of mouse embryonic stem cells into a myogenic lineage in vitro. In vivo, a mouse hindlimb ischaemia model was used to temporally investigate the ability of the $\mathrm{sLe}^{\mathrm{X}}$-matrix to induce bone marrow and local tissue responses for myogenesis and vasculogenesis in ischaemic skeletal muscle. The results suggest that the provision of a vascularised matrix environment can promote regenerative myogenesis in ischaemic muscle, supporting the $\mathrm{sLe}^{\mathrm{X}}$-matrix as a promising future therapy for muscle diseases.

\section{Materials and Methods}

Unless otherwise stated, all materials and reagents were obtained from Sigma-Aldrich (Oakville, Canada).

\section{Matrix preparation}

As previously described (Suuronen et al., 2009), 1 mM sLe ${ }^{\mathrm{x}}$ (Cedarlane Laboratories, Hornby, Canada) was prepared in $0.1 \mathrm{M}$ 2-( $N$-morpholino) ethanesulfonic acid (MES) buffer, at pH 5.0, containing 1:1 (molar equivalent) crosslinking mixture of $\mathrm{N}$-ethyl- $\mathrm{N}$-(3-dimethylaminopropyl) carbodiimide and N-hydroxysuccinimide (EDC/NHS; $13 \mathrm{mM}$ ). This mixture was subsequently mixed on ice with $1 \%$ porcine type I atelocollagen (w/v; Nippon Ham, Tskuba, Japan) with $40 \%$ (w/v) chrondroitin sulphate-C (CS-C; Wako Chemicals, Osaka, Japan) and thoroughly mixed, then diluted with phosphate buffered saline (PBS). The final concentration of each component was: $0.59 \%$ collagen (w/v), $2.35 \%(\mathrm{CS}-\mathrm{C})$ and $0.1 \mathrm{mM} \mathrm{sLe}^{\mathrm{x}}$. The final $\mathrm{pH}$ was adjusted to 7.2-7.4 using $1 \mathrm{~N} \mathrm{NaOH}$. Collagen-only matrices were prepared identically, but without $\mathrm{sLe}^{\mathrm{x}}$ in the mixture. For in vitro use, $150 \mu \mathrm{L}$ of each matrix was evenly spread into a well of a 6-well culture plate (BD Biosciences, Mississauga, Canada) using a cell scraper, resulting in an approximate thickness of $6 \mathrm{~mm}$. Materials were allowed $20 \mathrm{~min}$ at $37{ }^{\circ} \mathrm{C}$ to solidify. After gelation and hydration with media or PBS, the matrices display little affinity for TCPS and are easily removed. For in vivo application, materials were kept on ice and when required, $80 \mu \mathrm{L}$ was rapidly transferred to a syringe and subsequently injected.

\section{Compression testing}

Unconfined compression tests were performed using an MTS Bionix 858 servo-hydraulic material-testing system (MTS, Bellevue, WA, USA) equipped with a $5 \mathrm{~kg}$ load cell. Matrices $\left( \pm \mathrm{sLe}^{\mathrm{X}}\right)$ were swelled for $24 \mathrm{~h}$ in dPBS at $37^{\circ} \mathrm{C}$. Samples were cut using an $8 \mathrm{~mm}$ diameter punch, measured for thickness and placed inside of a plexiglass tank filled with dPBS for $1 \mathrm{~h}$ prior to testing at $37^{\circ} \mathrm{C}$. Samples were then placed between two non-porous stainless steel plates. Crosshead position and load were recorded using the Instron Wavemaker Software (version 7.0.0, Instron, Norwood, MA, USA) at a crosshead-speed of $50 \%$-per-minute and strained to a maximum of $20 \%$ strain. Each material was tested with $n=5$. Data were fitted to a stress-strain, 5-parameter double exponential growth model, as described (Millon et al., 2009):

$$
\sigma=\mathrm{y}_{0}+\mathrm{a}^{*} \exp \left(\mathrm{b}^{*} \varepsilon\right)+\mathrm{c}^{*} \exp \left(\mathrm{d}^{*} \varepsilon\right)
$$


where $\sigma$ is stress, $\varepsilon$ is strain, and $\mathrm{y}_{0}, \mathrm{a}, \mathrm{b}, \mathrm{c}$ and $\mathrm{d}$ are curvefitting parameters. The elastic modulus, as a function of strain was calculated by differentiating Eqn. (1):

$$
\sigma^{\prime}=a^{*} b^{*} \exp \left(b^{*} \varepsilon\right)+c^{*} d^{*} \exp \left(d^{*} \varepsilon\right)
$$

where $\sigma^{\prime}$ is the elastic (tangent) modulus, $\varepsilon$ is strain, and a, b, c and d are curve-fitting parameters. Elastic moduli are reported in $\mathrm{kPa}$ for the linear elastic region of the curves, which is the slope of the fitted curve in the linear region.

\section{Water contact angle assessment}

Contact angle measurements were performed on a VCA Optima (AST Products, Billerica, MA, USA) contact angle system that relies on the deformation of drops or bubbles by gravity. The instrument equipped with a motorised syringe allows a water drop $(5 \mu \mathrm{L})$ to be suspended from a syringe of known radius. The drop is held up initially by surface tension but soon is deformed by gravity. Matrices were swelled for $24 \mathrm{~h}$ in dPBS at $37^{\circ} \mathrm{C}$. Samples were cut using a $4 \mathrm{~mm}$ diameter punch, placed on the instrument's platform and tested immediately. Contact angle measurements were analysed using VCA Optima Image Analysis software ( $n=6$ for each material).

\section{Rheology}

Measurements of gelation time and viscosity were performed using a Brookfield R/S Plus Rheometer and a CC-3-50-2 R/S Spindle (Brookfield, Middleboro, MA, USA), as previously described (Deng et al., 2010). The maximum viscosity $\eta_{\max }$ and the time required to reach $\eta_{\max }\left(T_{\max }\right)$ were recorded for collagen- and $\mathrm{sLe}^{\mathrm{X}}$-matrices $(n=5$ each $)$

\section{Mouse embryonic stem cell culture}

D3 mouse embryonic stem cells (mESCs) were grown and differentiated as previously described (Kennedy et al., 2009). Briefly, the cells were aggregated at a density of $4 \times 10^{4}$ cells $/ \mathrm{mL}$ for 2 days in hanging drops and 5 days in non-tissue culture plates (Fisher Scientific, Ottawa, Canada). On day 7, the embryoid bodies were transferred to standard tissue culture polystyrene (TCPS) plates or tissue culture plates coated with either collagen or $\mathrm{SLe}^{\mathrm{X}}$-matrix. At the same time, some aggregates were transferred to coverslips coated with $0.1 \%$ gelatin (Fisher Scientific), collagen or $\mathrm{sLe}^{\mathrm{X}}$-matrix for later immunofluorescence analysis. On day 10, the medium (Dulbecco's Modified Eagle Medium (DMEM) High Glucose $+15 \%$ foetal bovine serum $(\mathrm{FBS})+1 \%$ non-essential amino acids $+1 \%$ pen-strip $+0.8 \%$ beta-mercaptoethanol) was changed to a low serum formulation (DMEM-F12 + 1\% penicillin-streptomycin $+1 \%$ N2 Supplement (Invitrogen/ Life Technologies, Burlington, ON, Canada)) and the cells were allowed to grow for 5 more days. On day 15, the cells were harvested from the tissue culture plates and fixed on coverslips. All experiments were performed in duplicate, with $n=6$.

\section{RNA extraction, cDNA synthesis and quantitative PCR}

Total RNA was extracted from cells and tissues using the RNeasy Kit (Qiagen, Streetsville, Canada) following the manufacturer's protocol. The first strand of cDNA was synthesised from $1 \mu \mathrm{g}$ RNA by reverse transcription using QuantiTect Reverse Transcription Kit (Qiagen). qPCR reactions were performed as previously described (Savage et al., 2009) using the primer sequences in Table 1. The reactions and data analysis were performed on an Epgradien S system (Eppendorf, Hamburg, Germany) using RealPlex version 2.2 software (Eppendorf). Relative gene expression was calculated using the comparative Ct method as described previously (Savage et al., 2009). Results for in vitro and in vivo tissue work were expressed as a ratio to $\beta$-actin and GAPDH, respectively. In vitro results were compared to results obtained on TCPS; in vivo results were compared to each animal's untreated, contralateral limb.

\section{Western blotting}

Cells were harvested for total protein extract with modified RIPA buffer (50 mM Tris-HCl, pH 7.4, 1 \% NP-40, $0.25 \%$ Na-deoxycholate, $150 \mathrm{mM} \mathrm{NaCl}, 1 \mathrm{mM}$ EDTA, $1 \mathrm{mM}$

Table 1. qPCR primer sequences used for analysis of murine transcripts in both tissue lysates and embryonic stem cell cultures.

\begin{tabular}{|c|c|c|}
\hline GENE & FORWARD PRIMER, 5' to 3' & REVERSE PRIMER, 5' to 3' \\
\hline GAPDH & TCGGTGTGAACGGATTTG & GGTCTCGCTCCTGGAAGA \\
\hline M-cadherin & CATCCCACCCATTAGTGTGTC & TCCCAGTGAACTTGTCGATAGA \\
\hline MHC3 & GCATAGCTGCACCTTTCCTC & GGCCATGTCCTCAATCTTGT \\
\hline MHC7 & GATGAGCAAGCCCTGGGCAGTC & TCAGAGCGCAGCTTCTCCACCT \\
\hline Myf5 & CCTGTCTGGTCCCGAAAGAAC & GACGTGATCCGATCCACAATG \\
\hline MyoD & CCCCGGCGGCAGAATGGCTACG & GGTCTGGGTTCCCTGTTCTGTT \\
\hline Myogenin & GCAATGCACTGGAGTTCG & ACGATGGACGTAAGGGAGTG \\
\hline Pax3 & TTTCACCTCAGGTAATGGGACT & GAACGTCCAAGGCTTACTTTGT \\
\hline Pax7 & CTCAGTGAGTTCGATTAGCCG & AGACGGTTCCCTTTGTCGC \\
\hline Six1 & TAACTCCTCCTCCAACAAGCA & CGAGTTCTGGTCTGGACTTTG \\
\hline$\beta$-actin & AAATCGTGCGTGACATCAAA & AAGGAAGGCTGGAAAAGAGC \\
\hline
\end{tabular}


phenylmethylsulfonyl fluoride (PMSF) with a protease inhibitor cocktail (Roche, Laval, Canada). Protein was separated on a $10 \%$ SDS PAGE gel in a $1 \times$ Running Buffer and transferred to an Immunoblot polyvinylidene fluoride (PVDF)-membrane (BioRad, Saint-Laurent, Canada). Anti-Pax3 (1:300, R\&D Systems, Minneapolis, MN, USA) was used and visualised with HRP-conjugated secondary antibodies. Blots were enhanced using Western Blot Signal Enhancer (Fisher Scientific) before blocking with $5 \%$ Milk in Tris-buffered saline/Tween (TBST).

\section{Immunofluorescence}

mESCs were fixed in cold methanol and incubated with mouse anti-myosin heavy chain (MHC) monoclonal antibody MF20 (Developmental Studies Hybridoma Bank, Iowa City, IA, USA) overnight at $4{ }^{\circ} \mathrm{C}$. Goat anti-mouse IgG $(\mathrm{H}+\mathrm{L})$ Cy3-linked secondary antibody (Jackson ImmunoResearch Laboratories, West Grove, PA, USA) was used to visualise MHC3 protein expression. Hoechst dye was used for nuclear staining. Images were acquired with an Olympus (Tokyo, Japan) BX50 microscope using Image Pro Plus (MediaCybernetics, Rockville, MD, USA). Fusion index was reported as the percentage of nuclei per field-of-view (FOV) that are in multi-nucleated cells, indicating that cell fusion has occurred.

\section{Animal model}

All procedures were performed with approval of the University of Ottawa Animal Care Committee, in compliance with the National Institute of Health's Guide for the Care and Use of Laboratory Animals. To investigate the endogenous bone marrow response, a green fluorescent protein (GFP) bone marrow transplantation (BMTx) was performed, as previously described (Whitman et al., 2004). Briefly, 8-9 week-old female C57BL/6J mice (Jackson Laboratories, Bar Harbor, ME, USA) were irradiated with a total of 900 rads from a caesium source, delivered $3 \mathrm{~h}$ apart in 2 equal doses. Donor bone marrow cells $\left(7 \times 10^{6}\right)$ from a transgenic GFP mouse (C57BL/6-Tg(CAG-EGFP)10sb/J; Jackson Laboratories) were injected into the tail vein of irradiated recipient mice in a total volume of $150 \mu \mathrm{L}$ dPBS. Six weeks after BMTx, proximal femoral arteries in left hind-limbs were ligated, as described (Limbourg et al., 2009), using 4.0 silk thread, under $2 \%$ isoflurane. Gastrocnemius muscles, downstream of the ligation site, subsequently received an $80 \mu \mathrm{L}$ injection of: $\mathrm{dPBS}(n=9)$, collagen matrix $(n=8)$, or $\mathrm{sLe}^{\mathrm{X}}$-matrix $(n=8)$, using a 27-gauge needle (BD Biosciences) in 3 equivolumetric injections spaced throughout the muscle. Animals were sacrificed on day 14. To further characterise the myogenic response without the effects of a BMTx, the same procedure was performed on wild-type C57BL/6J mice without a BMTx, and animals were sacrificed on day 3 or day 10 ( $n=6$ for all treatments per time point). Additional age-matched, untreated animals (no ligation surgery or treatment) were sacrificed as baseline controls $(n=6)$.

\section{Flow cytometry}

Blood samples $(\sim 100 \mu \mathrm{L})$ were procured from the right saphenous veins on days 0 (pre-operative/baseline), 1 , 4, 7 and 14 post-operatively. As previously described
(Suuronen et al., 2009), CACs were isolated using density-gradient centrifugation on Histopaque 1077 and immediately stained with the following antibodies: antic-kit (Southern Biotech, Birmingham, AL, USA), antiCXCR4 (BD Biosciences) and anti-flk-1 (eBioscience, San Diego, CA, USA). Cells were analysed with a FACSAria flow cytometer (BD Biosciences). Isotype, fluorochromematched immunoglobulin antibodies were used as controls. CAC expression of a particular antigen is presented as relative to its baseline value (at day 0 ).

\section{Laser Doppler}

Perfusion was assessed using laser Doppler pre-operatively (baseline) and on days 4 and 14, as previously described (Kuraitis et al., 2011a). Briefly, under $2 \%$ isoflurane, a multi-fibre needle probe ( 8 separate collecting fibres; Moor Instruments, Axminster, UK) was used to evaluate perfusion in both treated and untreated hind-limbs. Data are reported as perfusion indexes, calculated as a ratio of perfusion in treated:untreated hind-limbs.

\section{Immunohistochemistry}

Gastrocnemius muscles from BMTx mice were collected and fixed overnight in $4 \%$ paraformaldehyde before paraffinisation. All samples were analysed in crosssection. Samples were de-paraffinised and hydrated with sequential washes in toluene and decreasing concentrations of ethanol. Antigen retrieval was performed using boiling citrate buffer ( $\mathrm{pH}$ 5.6). All staining was performed in PBS containing $10 \%$ normal horse serum (Vector Laboratories, Burlington, Canada). The following antibodies were used: anti- $\alpha$-SMA (pre-diluted, Abcam, Cambridge, MA, USA), anti-GFP (1:100; Abcam), and anti-CXCR4 (1:50; Abcam). Hindlimbs from non-BMTx mice were collected and placed in OCT solution before being frozen in liquid nitrogen. Tissue sections were stained with antiactive caspase-3 antibody (1:50; Abcam), and myofibre borders were visualised using wheat germ agglutininTexas Red (Invitrogen, Burlington, Canada), following the manufacturer's protocol. For all analyses: sections were $5 \mu \mathrm{m}$ in thickness; mounting medium with DAPI (Vector Laboratories) was used to visualise nuclei; and measurements and cell counts were determined from 6 random microscopic FOV, taken by a blinded observer with a (Oberkochen, Germany) Zeiss AxioObserver Z1 microscope and visualised with Axiovision. Counts were averaged from two blinded observers. The cross-sectional area (CSA) of arterioles was determined using Image Pro Plus.

\section{Cytokine arrays}

As previously described (Kuraitis et al., 2011a), hindlimbs were lysed under liquid nitrogen, and cytokine arrays (Raybiotech, Norcross, GA, USA) were performed according to the manufacturer's recommendations. Custom cytokine arrays were used to analyse the protein levels of basic fibroblast growth factor (bFGF), insulin-like growth factor-I (IGF-I), IGF binding proteins-2 and -5 (IGFBP-2, -5), interleukin-10 (IL-10), L-selectin, P-selectin, stromal cell-derived factor- $1 \alpha$ (SDF-1 $\alpha)$, tissue inhibitor of matrix metalloproteinase-2 (TIMP-2), tumour necrosis factor- $\alpha$ 
(TNF $\alpha$ ), vascular cell adhesion molecule-1 (VCAM-1), and vascular endothelial growth factor (VEGF). Arrays were performed with $n=5$ for each group evaluated.

\section{Functional assessment of treated muscle}

A subset of mice that received PBS or one of the matrix treatments into the ischaemic hind-limb ( $n=6$ per group) were sacrificed at day 10 for functional assessment of the treated muscle. Untreated wild-type animals were included as controls. Soleus muscles were carefully isolated and maintained in a continuously oxygenated Krebs-Ringer bicarbonate buffer solution. One end of the muscle was linked to a fixed clamp and the other end to the lever arm of an Aurora Scientific Instruments (Aurora, ON, Canada) 300B actuator/transducer system. Muscles were electrically stimulated via two platinum electrodes and cross-sectional area, twitch force, maximum force, power decrease and time to fatigue were recorded as previously described (Del Prete et al., 2008). Cross-sectional area measurements allowed for calculation of specific force values.

To assess the functional recovery of treated muscles, animals were subjected to a forced treadmill protocol. They were conditioned to the treadmill process for 1 week prior to final testing at an incline of $0^{\circ}$ for $5 \mathrm{~min}$ at $5 \mathrm{~m} / \mathrm{s}$ and $5 \mathrm{~min}$ at $10 \mathrm{~m} / \mathrm{s}$. Animals that did not maintain the treadmill speed received a shock of $0.5 \mathrm{~mA}$. The maximal test of exhaustion was modified from Ferreira et al. (Ferreira et al., 2008). In brief, the treadmill speed increased every $3 \mathrm{~min}$ at a rate of $3 \mathrm{~m} / \mathrm{min}$. Animals were removed from the treadmill when they could no longer manage to return to the treadmill from the shock platform. Total distance and speed at which exhaustion occurred were recorded $(n=5)$.

\section{Statistical analysis}

Comparisons between multiple groups were performed using a one-way analysis of variance with Tukey's posthoc test. Comparisons between repetetitive stimulation in power measurements were performed using a two-way analysis of variance with Bonferroni's post-hoc test. Comparisons between two groups were performed using a 2-tailed Student's $t$-test. (SPSS; IBM, Somers, NY, USA). Unless otherwise stated, values are expressed as means \pm standard error. $p$ values of $<0.05$ were considered statistically significant.

\section{Results}

\section{Mechanical properties of the matrices are similar to those of skeletal muscle}

It is known that a substrate's mechanical properties (such as stiffness) are important for regulating the development and maintenance of muscle (Engler et al., 2004; Engler et al., 2006). Therefore, the physical properties of $\mathrm{sLe}^{\mathrm{X}}$-matrix and collagen-only matrix were tested to determine if these fell within the range considered favourable for the support of skeletal muscle. Rheological assessment revealed that the addition of $\mathrm{sLe}^{\mathrm{X}}$ to the collagen matrix did not alter the time to gelation at $37^{\circ} \mathrm{C}(p=0.7$; Fig. $1 \mathrm{~A})$, nor did it change the viscosity of the material upon gelation $(p=1.0$;
Fig. 1B). Both matrices (with and without the addition of $\mathrm{sLe}^{\mathrm{X}}$ ) displayed a gradual increase in stiffness and showed a linear stress-strain response up to $12 \%$ strain, followed by a non-linear response (Fig. 1C). In this linear region, the elastic modulus ( $\left.\sigma^{\prime}\right)$ for the collagen matrix was $5.85 \pm 0.06 \mathrm{kPa}$. Incorporation of $\mathrm{sLe}^{\mathrm{X}}$ into the matrix increased the modulus to $7.51 \pm 0.07 \mathrm{kPa}(p=0.013)$. These moduli are similar to the range of native skeletal muscle elasticity (Engler et al., 2006). Water contact angles were not measurable on the collagen matrix (Fig. 1D), due to its extreme hydrophilicity and water content; however, the addition of $\mathrm{sLe}^{\mathrm{X}}$ generated areas on the matrices where contact angle was measured at $48.1^{\circ} \pm 3.2$, indicating the presence of less hydrophilic areas within the matrix (Fig. 1E). To summarise, our mechanical analysis revealed that the elastic moduli of the matrices are similar to that of skeletal muscle.

\section{Matrices facilitate myogenic differentiation of murine embryonic stem cells}

To study the myogenic properties of the matrices, we compared the differentiation of murine embryonic stem cells (mESCs) on the $\mathrm{sLe}^{\mathrm{x}}$-matrix versus collagen-only matrix and tissue culture polystyrene (TCPS) substrates over a period of 8 days, after 7 days of embryoid body formation. The culture of mESCs on collagen and/or $\mathrm{sLe}^{\mathrm{x}}$-matrix increased mRNA levels for factors involved in myogenic progenitor formation, myogenic regulation, and final muscle development (Fig. 2A-H). Collagen matrix and $\mathrm{sLe}^{\mathrm{X}}$-matrix increased mRNA levels of Pax 3 $(p<0.03$; Fig. 2C), MHC3 ( $p<0.05$; Fig. 2D), myogenin ( $p \leq 0.1$; Fig. 2E) and troponin-C ( $p<0.05$; Fig. $2 \mathrm{H})$. Only culture on collagen matrix increased Pax 7 mRNA levels ( $p=0.02$; Fig. 2B) and Myf5 ( $p=0.01$; Fig. 2F). Differences in mRNA were not noted for Six1 (Fig. 2A) or MyoD (Fig. 2G). An increase in the protein level of Pax3 in cells cultured on either matrix was detected by Western blotting (Fig. 2I). The fusion index was greater for both matrix treatments (Fig. 2J). Immunofluorescence staining demonstrated increased MHC protein in mESCs cultured on matrix versus TCPS (Fig. 2K-M). These results demonstrate that the matrices enhanced skeletal myogenesis in mESCs, indicated by the upregulation of skeletal muscle markers.

\section{Myocyte regeneration is enhanced 10 days post- matrix treatment}

Regenerative myogenesis was quantified in sections of hind-limb muscle by the number of myocytes with centralised nuclei, which represent young myocytes under 1-month of age (Sun et al., 2009). Data are reported as the percentage of myocytes with centralised nuclei (termed regenerating myocytes). At day 14 , the $\mathrm{sLe}^{\mathrm{x}}$-matrixtreated animals had 8.1-fold more regenerating myocytes, compared to PBS ( $p=0.005$; Fig. 3A). To better understand the myogenic regenerative process of the ischaemic muscle in response to our treatment temporally, additional mice were evaluated 3 and 10 days after treatment. At day 3 , mice did not show any differences in regenerating myocytes between treatment groups ( $p=0.8$; Fig. 3A-D). 

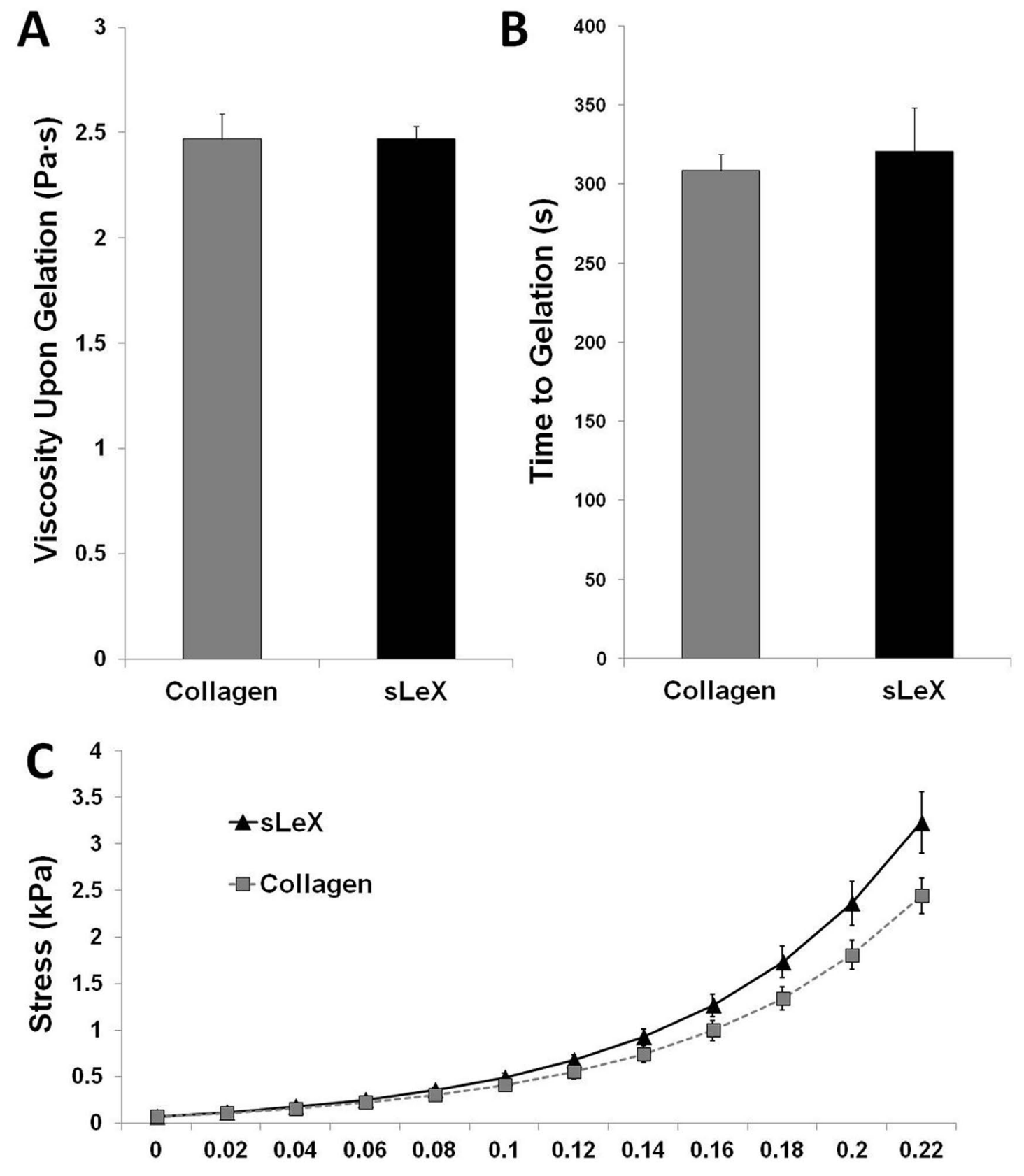

Strain
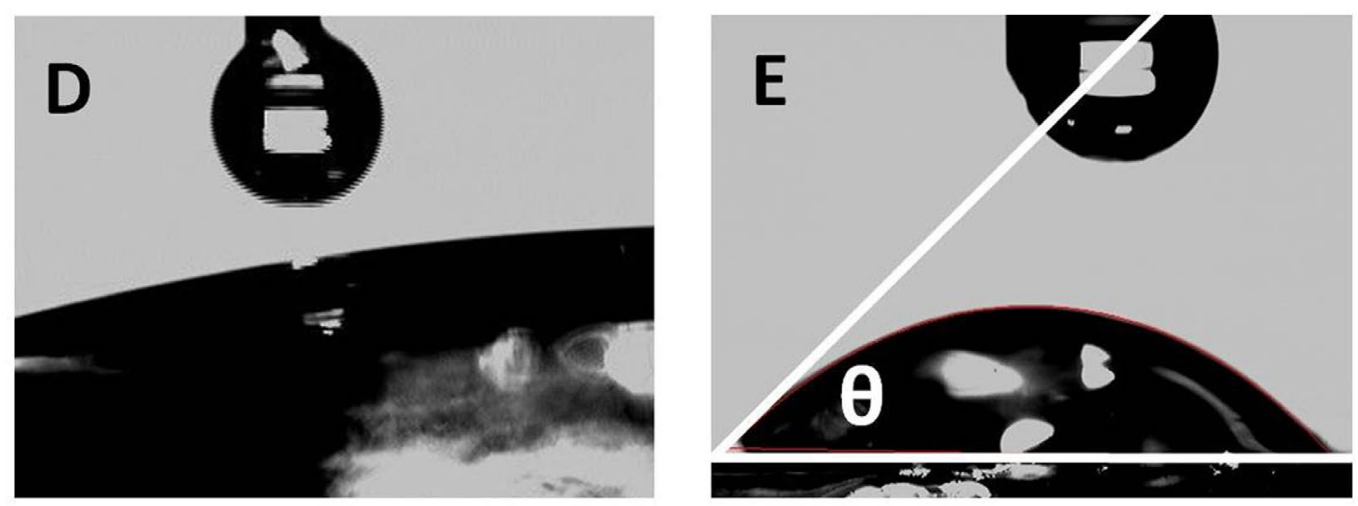

Fig. 1. Characterisation of matrices' mechanical properties. (A) Average viscosity upon gelation $\left(\eta_{M A X}, P a \cdot s\right)$, and (B) average time to gelation $\left(T_{\mathrm{MAX}}, \mathrm{s}\right)$ measurements for the collagen matrix and the $\mathrm{sLe}^{\mathrm{X}}$-matrix. (C) Stress-strain curves for the 2 matrices at $20 \%$ strain and a $50 \% / \mathrm{min}$ strain rate. (D, E) Representative images of water contact angle $(\theta)$ for collagen (D) and $\operatorname{sLe}^{\mathrm{X}}$-matrix (E); water contact angle of $\theta=46^{\circ}$ is shown. Histograms in $\mathbf{A}$ and $\mathbf{B}$ represent data from $n=4$ different samples, and in $\mathrm{C}$ are from $n=5$ different samples. Water contact angle images in $\mathbf{D}$ and $\mathbf{E}$ are representative of $n=6$ separate samples per group. 

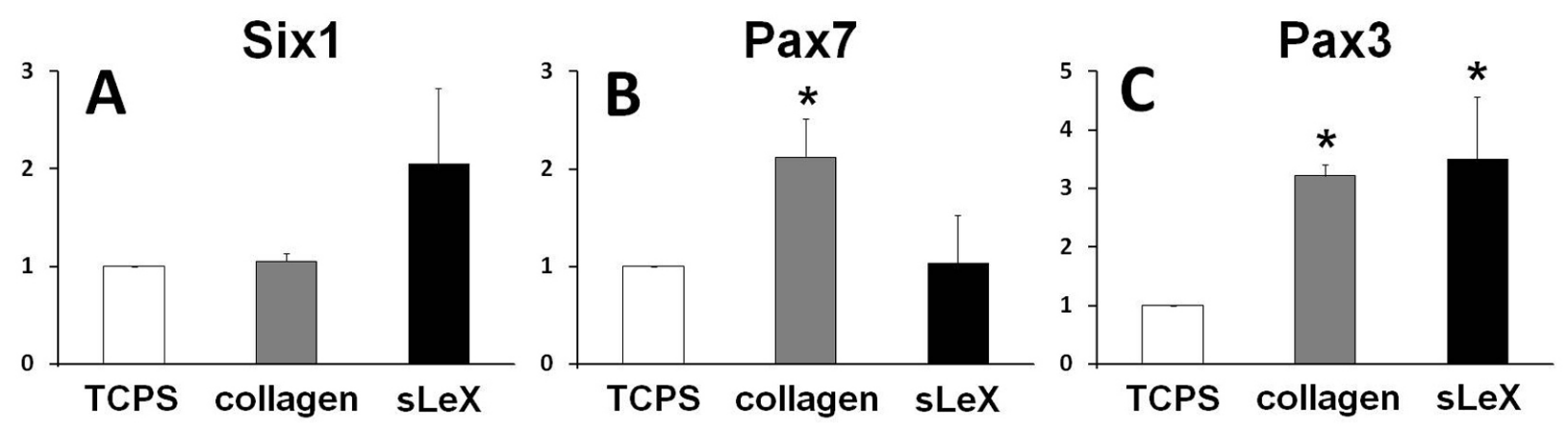

MHC3

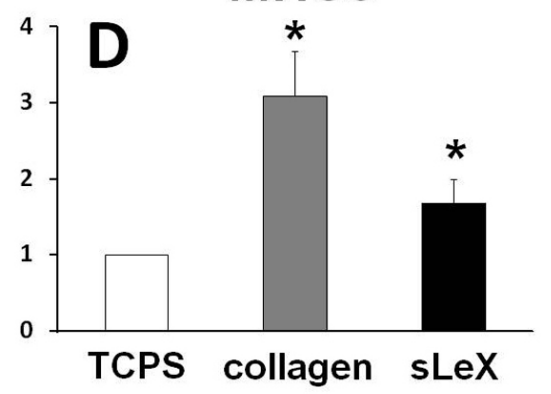

Myogenin
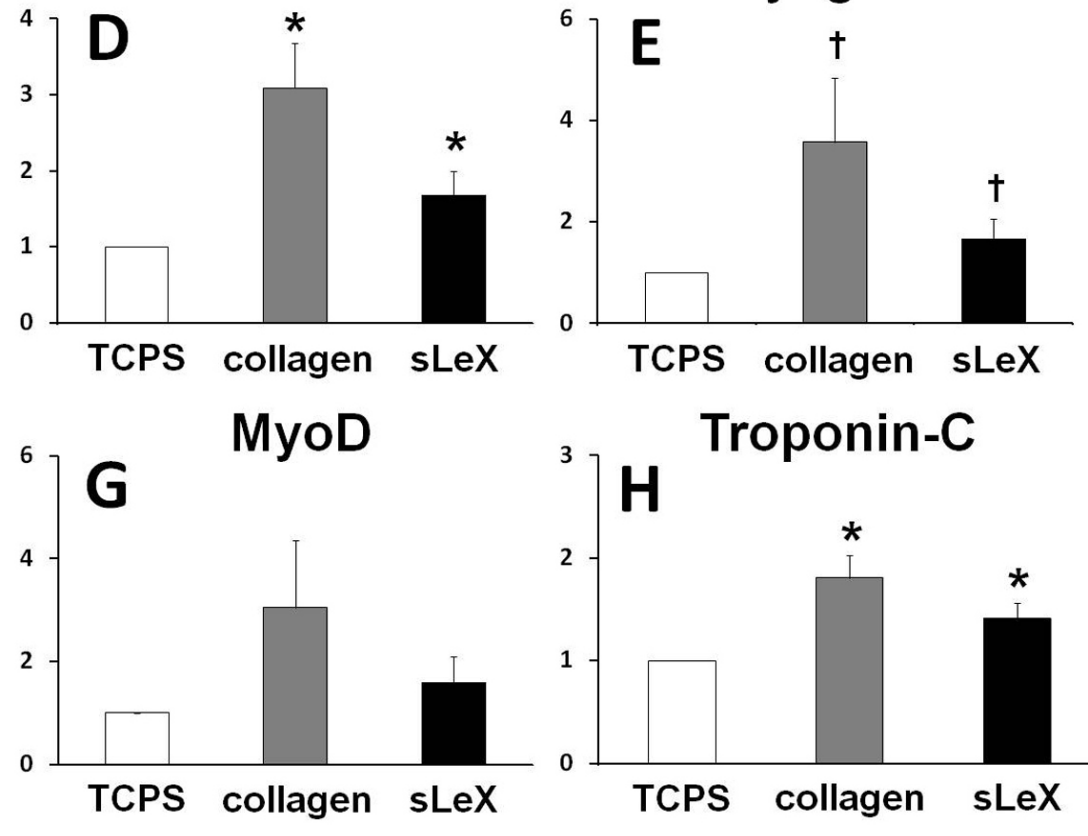

Myf5
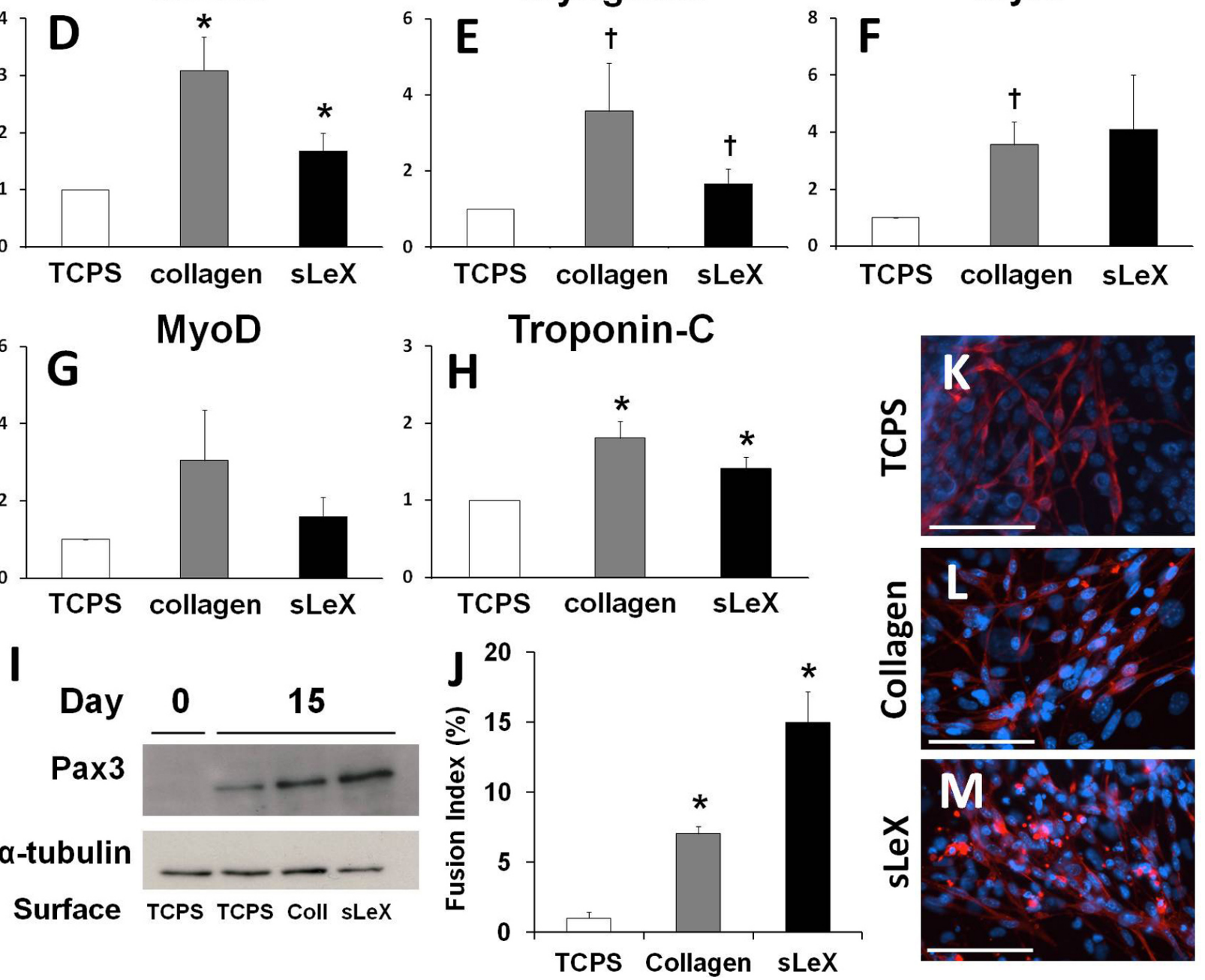

Fig. 2. Matrices augment myogenic differentiation of murine embryonic stem cells. (A-H) mESCs were differentiated for 8 days on collagen matrix or $\mathrm{sLe}^{\mathrm{x}}$-matrix (after 7 days of EB formation) and $\mathrm{mRNA}$ levels for several myogenic factors were measured by q-PCR, and compared to culture on tissue culture polystyrene plates (TCPS). The y-axis for all graphs represents the fold-difference relative to TCPS. (I) Pax3 protein expression in mESCs differentiated on the 3 substrates was measured by Western blot. Myocyte fusion was increased in both matrix treatments (J). (K-M) Hoechst staining (blue) and immunofluorescence staining for MHC (red) in differentiated mESCs. Scale bars $=180 \mu \mathrm{m} .{ }^{*} p<0.05$ and ${ }^{\dagger} 0.05<p<0.1 v s$. TCPS. Results are from 2 ( $n=6$ total per group; in duplicate for A-G) independent experiments.

However, at day 10 , the $\mathrm{sLe}^{\mathrm{x}}$-matrix treatment significantly increased the regenerating myocyte number by 4.5 -fold compared to the PBS group ( $p=0.02$; Fig. 3A, E, G).

Similarly, differences in the mRNA levels of several skeletal muscle markers in ischaemic hind-limbs were not noted between treatment groups at day 3 . The exception was Pax 7 (marker for skeletal muscle satellite cell), which was greatest in PBS-treated animals compared to treatment with collagen matrix (13.9-fold; $p=0.007)$ or with $\mathrm{sLe}^{\mathrm{x}}$ matrix (6.1-fold; $p=0.02$; Fig. 4A). However, at day 10 , matrices induced the transcription of several myogenic factors (Fig. 4B), compared to PBS. Specifically, treatment 
A

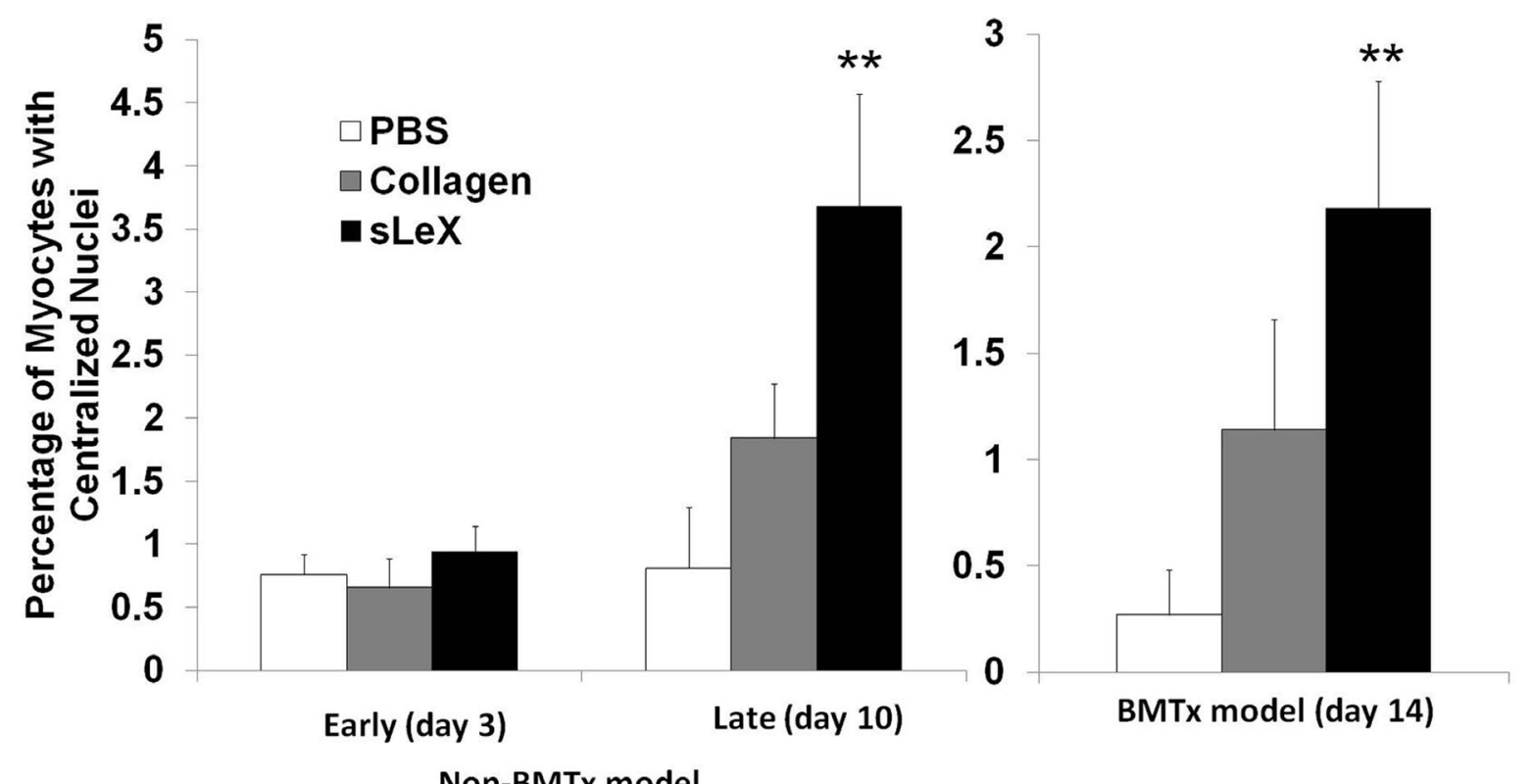

Non-BMTx model
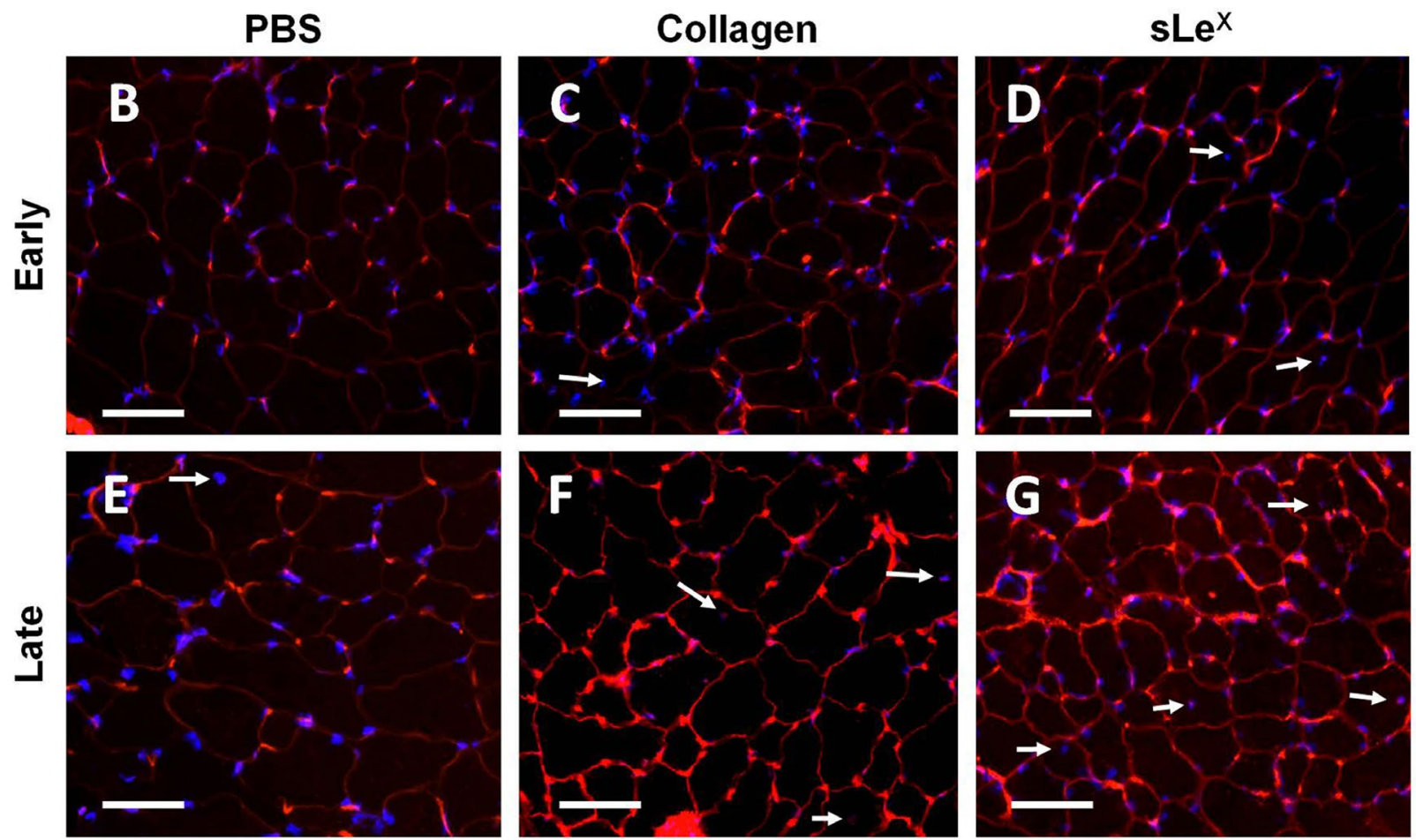

Fig. 3. Regenerative myogenesis is enhanced after treatment with $\mathrm{sLe}^{\mathrm{x}}$-matrix. (A) The number of regenerating myocytes (identified by centralised nuclei) per FOV in hind-limb muscle sections in non-BMTx model, 3 and 10 days after treatment, and in the BMTx model, 14 days after treatment. (B-G) Double immunofluorescent staining for nuclei (DAPI) and myocyte borders (wheat germ agglutinin-Texas Red (red)) in early- (day 3; B-D) and late- (day 10 ; E-G) stage cross-sections of hind-limb muscle (non-BMTx model). Scale bars $=50 \mu \mathrm{m}$. $* * p \leq 0.01 v s$. PBS of the same day. Results are representative of $n=8-9$ (BMTx model) and $n=6$ (non-BMTx model) separate mice per treatment group per time point.

with $\mathrm{sLe}^{\mathrm{x}}$-matrix upregulated the hind-limb tissue mRNA levels of the MRFs MyoD (3.7-fold; $p=0.06$ ), myogenin (8.1-fold; $p=0.007$ ) and Myf5 (3.4-fold; $p=0.007$ ), as well as Six1 (2.1-fold; $p=0.04)$, and the satellite cell markers Pax7 (8.5-fold; $p=0.06$ ) and M-cadherin (3.5fold; $p=0.01$ ). There was a favourable trend for collagen matrix treatment to up-regulate the muscle differentiation marker MHC3 (3.2-fold; $p=0.06$ ), the MRF Myf5 (1.6fold; $p=0.09$ ), and Six1 (2.3-fold; $p=0.1)$. Overall, both matrices increased the transcription of myogenic genes. Although no differences were detected between the 2 matrices, only treatment with $\mathrm{sLe}^{\mathrm{x}}$-matrix resulted 
A Early (Day 3)
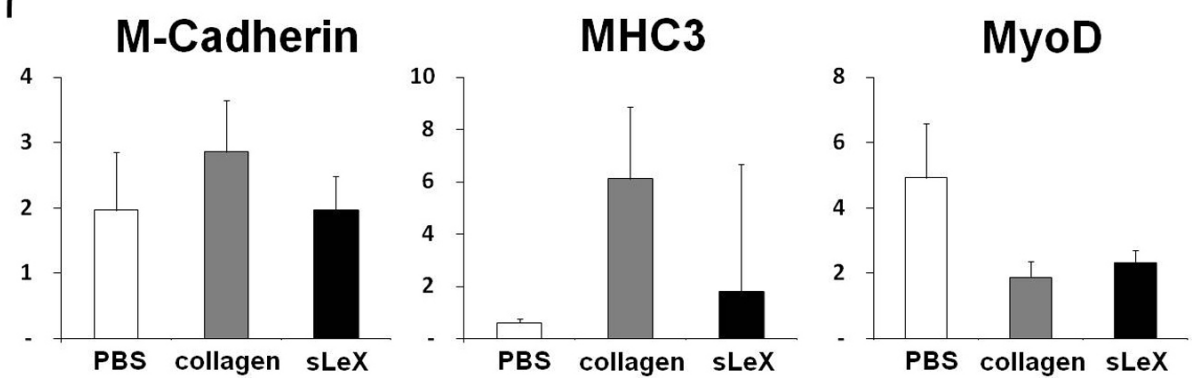

Myogenin
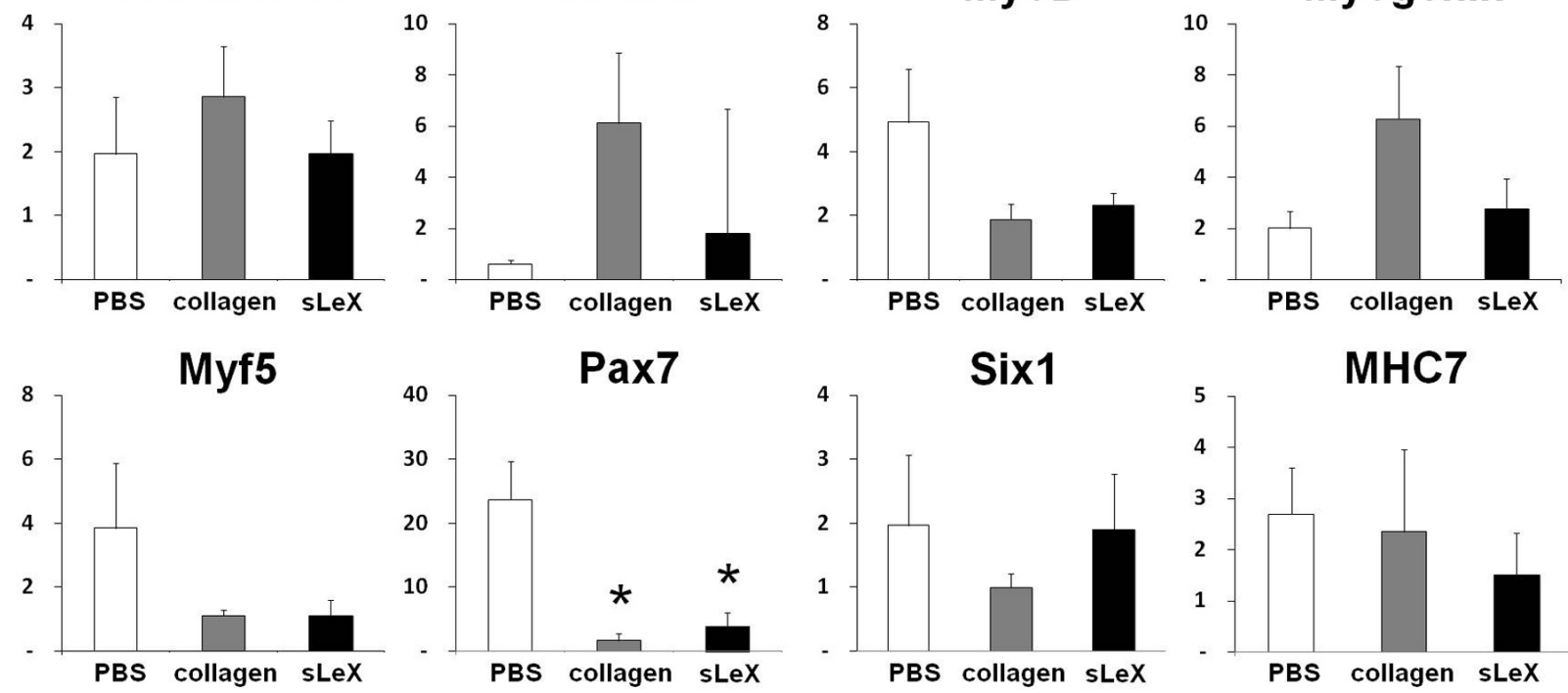

B

Late (Day 10)

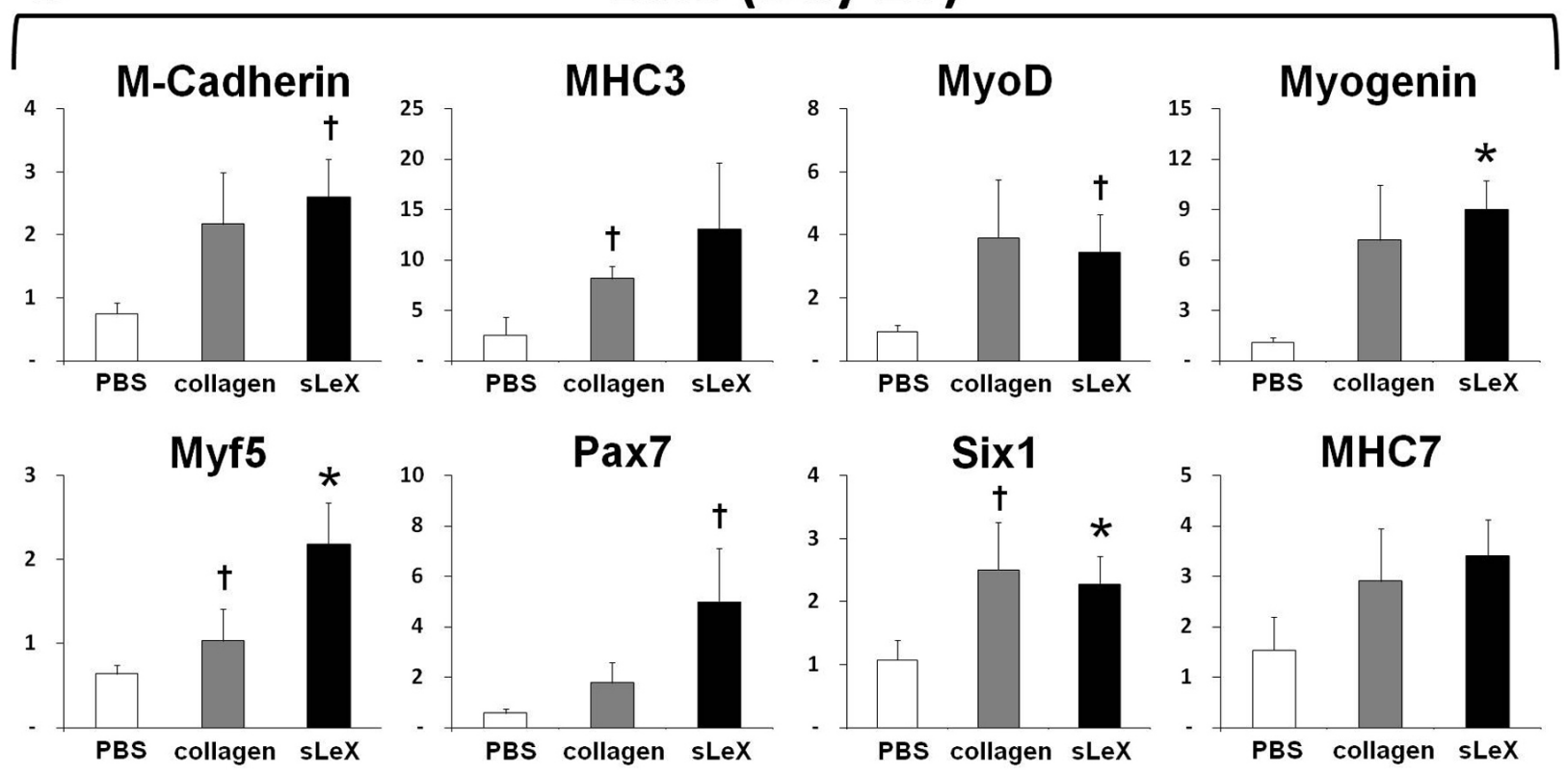

Fig. 4. Treatment with $s L e^{x}$-matrix increases the transcription of myogenic factors in the hind-limb muscle. (A) qPCR analysis of myogenic transcripts in hind-limb tissue at 3 days after treatment (non-BMTx model). (B) qPCR analysis of myogenic transcripts in hind-limb tissue at 10 days after treatment (non-BMTx model). The y-axis for all graphs represents the fold-difference relative to the untreated, contra-lateral limb. ${ }^{\dagger} 0.05<p<0.1 v s$. PBS; ${ }^{*} p<0.05 v s$. PBS. Results are from $n=6$ different mice per group per time point.

in significantly elevated levels of some of these genes compared to PBS, and only the $\mathrm{sLe}^{\mathrm{x}}$-matrix treatment increased the number of new myocytes.

\section{Cytoprotection is conferred by matrices}

The level of ischaemia-induced apoptosis, as determined by positive staining for active caspase-3, was assessed in hind-limbs. At day 3, hind-limbs of PBS and collagen matrix treatments had 1.47- $(p=0.01)$ and 1.51-fold
( $p=0.01)$ more apoptotic cells, respectively, than those treated with $\mathrm{sLe}^{\mathrm{x}}$-matrix (Fig. 5A). Later, at day 10 , there was no longer a difference in local apoptosis between the two matrix treatments, but PBS-treated hind-limbs maintained more apoptotic cells than those which received collagen matrix (by 2.1-fold; $p=0.02$ ) or $\mathrm{sLe}^{\mathrm{X}}$-matrix (by 3.4-fold; $p=0.0002$; Fig. 5A-D). From day 3 to day 10, the number of apoptotic cells in $\mathrm{SLe}^{\mathrm{X}}$-matrix-treated hindlimbs did not change $(p=0.4)$, but a reduction $(0.6$-fold $)$ 
Fig. 5. Reduced apoptosis is observed in hind-limbs treated with sLe ${ }^{\mathrm{x}}$-matrix. (A) The number of apoptotic cells (positive for active caspase-3) per FOV in hind-limb muscle sections at 3 and 10 days post-treatment (normalised to PBS). (B-D) Double immunofluorescence for the detection of active caspase-3 (green) and nuclei (DAPI) in hind-limb muscle sections. Scale bars $=30 \mu \mathrm{m} .{ }^{*} 0.05<p<0.1$ vs. collagen; $* * p<0.05$ vs. all others; ${ }^{\#} 0.05<p<0.1$ between days 3 and $10 ; \# p<0.05$ between days 3 and 10. Results are from $n=6$ different mice per group per time point.
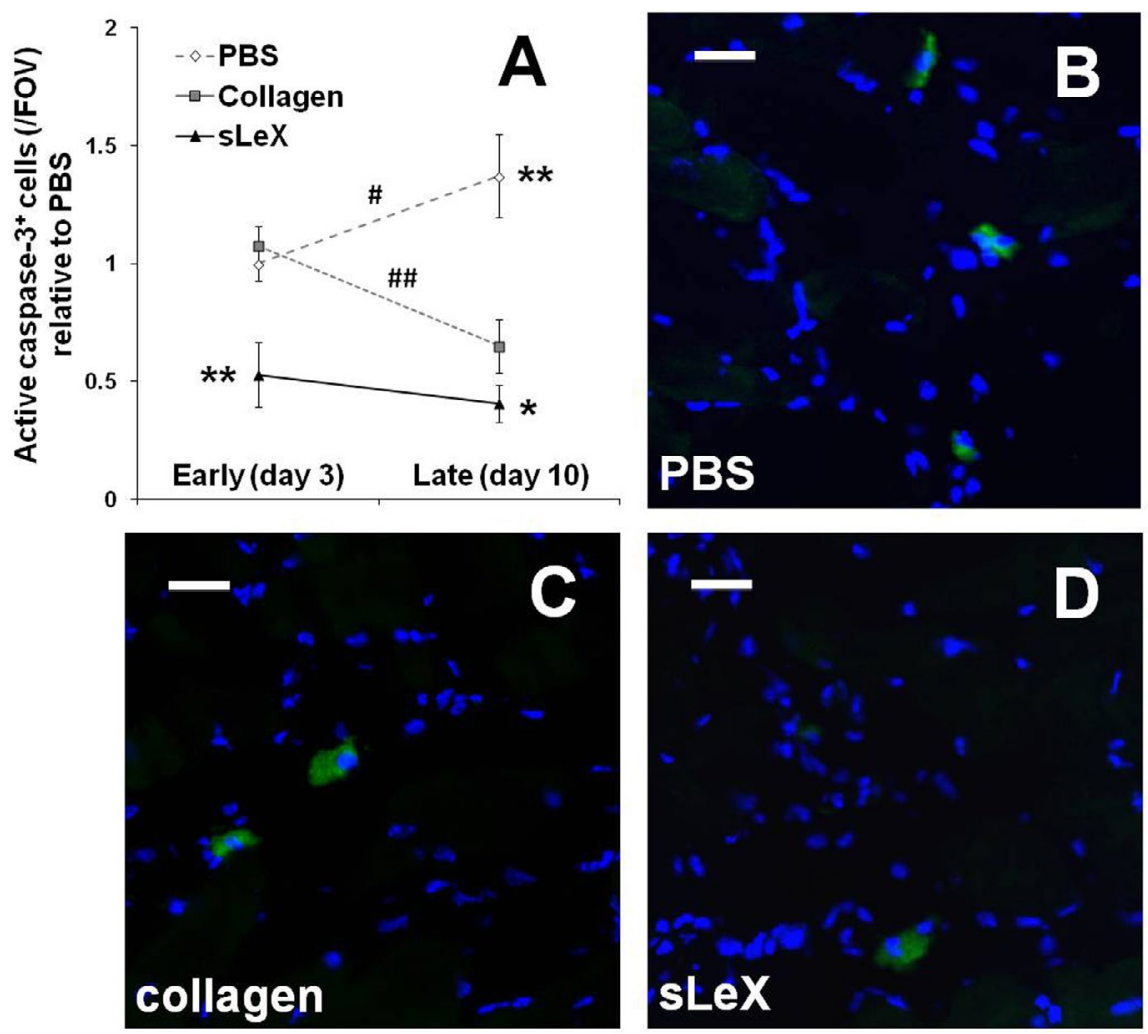

was observed for collagen matrix treatment $(p=0.02)$. A trend for increased apoptosis (by 1.4-fold) was observed for the PBS treatment $(p=0.07)$.

Treatment with $s L e^{\mathrm{x}}$-matrix improves arteriogenesis and restores perfusion

The same hind-limb ischaemia model was used to assess matrix effects on vascular regeneration, but using a bone marrow transplantation (BMTx) model. We have previously demonstrated that an injectable matrix can restore perfusion to ischaemic muscle (Suuronen et al., 2009), and wanted to identify the role of bone marrowderived progenitors in this phenomenon. Bone marrow reconstitution was performed using donor bone marrow cells from a transgenic green fluorescent protein (GFP) mouse, so that the mobilised bone marrow cells could be tracked using immunohistochemistry and flow cytometry. Laser Doppler analysis demonstrated that the ligation surgery reduced perfusion in the hind-limb by approximately $50 \%$. Four days after ligation surgery and treatment injection, there was no difference in perfusion among the treatment groups (Fig. 6A; $p=0.6$ ). At day 14, $\mathrm{SLe}^{\mathrm{X}}$-matrix treatment restored perfusion to a level that was $85 \%$ greater than the PBS group ( $p=0.01)$, and $24 \%$ greater than the collagen matrix group ( $p=0.03$; Fig. 6A).

Although hind-limb arteriole density (determined by immunofluorescence with $\alpha$-smooth muscle actin (SMA)) did not differ between matrix treatments $(p=0.7)$, it was increased in both the $\mathrm{sLe}^{\mathrm{x}}$-matrix and collagen matrix groups by 1.8- $(p=0.01)$ and 1.7-fold $(p=0.01)$, respectively, compared to PBS treatment (Fig. 6B-E). Upon examination of arteriolar size, the mean cross-sectional area of arterioles of $\mathrm{sLe}^{\mathrm{x}}$-matrix-treated animals was 3.2- and 5.2-fold greater than that of the collagen matrix $(p=0.01)$ and the PBS-treated animals, respectively ( $p=0.003$; Fig. $6 \mathrm{~F})$. A trend for increased arteriolar area by 1.6 -fold was observed for treatment with collagen matrix compared to PBS $(p=0.08)$. To summarise, the $\operatorname{sLe}^{\mathrm{X}}$-matrix induced the formation of arterioles of greater size, accompanied by a greater restoration of blood flow.

The sLe $^{\mathrm{x}}$-matrix mobilises CACs from bone marrow Marrow-derived progenitor cells $\left(\mathrm{GFP}^{+}\right.$cells) that were mobilised to the circulation were characterised by flow cytometry using antibodies for the CAC markers c-kit, flk-1 and CXCR4. At early time points after intramuscular delivery of the treatment (days 1-4), the sLe $\mathrm{x}^{\mathrm{X}}$-matrix increased $\mathrm{GFP}^{+} \mathrm{c}-\mathrm{kit}^{+}$cells in the circulation by 1.4 -fold, compared to PBS (Fig. 7A; $p=0.001$ ). Both collagen and $\mathrm{sLe}^{\mathrm{X}}$-collagen matrices increased the frequency of $\mathrm{GFP}^{+}$flk- $1^{+}$cells by 2.1 - and 2.3-fold, respectively (Fig. $7 \mathrm{~A} ; p=0.03,0.006$ ). At later time points (days 7-14), continued effects of the $\mathrm{sLe}^{\mathrm{X}}$-collagen matrix treatment on bone marrow cell mobilisation were observed (Fig. 7A). Specifically, the $\mathrm{sLe}^{\mathrm{x}}$-matrix treatment increased circulating $\mathrm{GFP}^{+} \mathrm{CXCR} 4^{+}$cells compared to both $\mathrm{PBS}$ $(1.7$-fold; $p=0.04)$ and collagen matrix (1.5-fold; $p=0.02)$ treatments. In addition, $\mathrm{sLe}^{\mathrm{X}}$-matrix treatment increased $\mathrm{GFP}^{+}$flk- $1^{+}$cells by 2.3 -fold $(p=0.001)$ compared to PBS, and by 1.4 -fold $(p=0.02)$ compared to collagen matrix. Collagen matrix and $\mathrm{sLe}^{\mathrm{x}}$-matrix increased $\mathrm{GFP}^{+} \mathrm{c}-\mathrm{kit}^{+}$ cells by 1.5 -fold $(p=0.03)$ and 2.1 -fold $(p=0.0001)$, respectively, compared to $\mathrm{PBS}$. Overall, these results demonstrate the ability of the $\mathrm{sLe}^{\mathrm{x}}$-matrix to increase the mobilisation of CACs from the bone marrow. 




Fig. 6. The $\mathrm{sLe}^{\mathrm{x}}$-matrix improves perfusion of ischaemic hind-limbs and augments arteriole formation. (A) Hindlimb perfusion measured by laser Doppler analysis up to 2 weeks after treatment with PBS, collagen or sLe ${ }^{\mathrm{X}}$-matrix. (B-D) Double immunofluorescence images of hind-limb muscle for $\alpha$-SMA (red) and nuclei (DAPI). (E) The number of arterioles quantified in hind-limb muscle sections. (F) Assessment of the average arteriolar lumen size (area) in hind-limb muscle. Scale bars $=125 \mu \mathrm{m} . * p<0.05 v s$. PBS; $* * p \leq 0.01 v s$. all others. Results represent data from $n=8-9$ separate mice per group. 

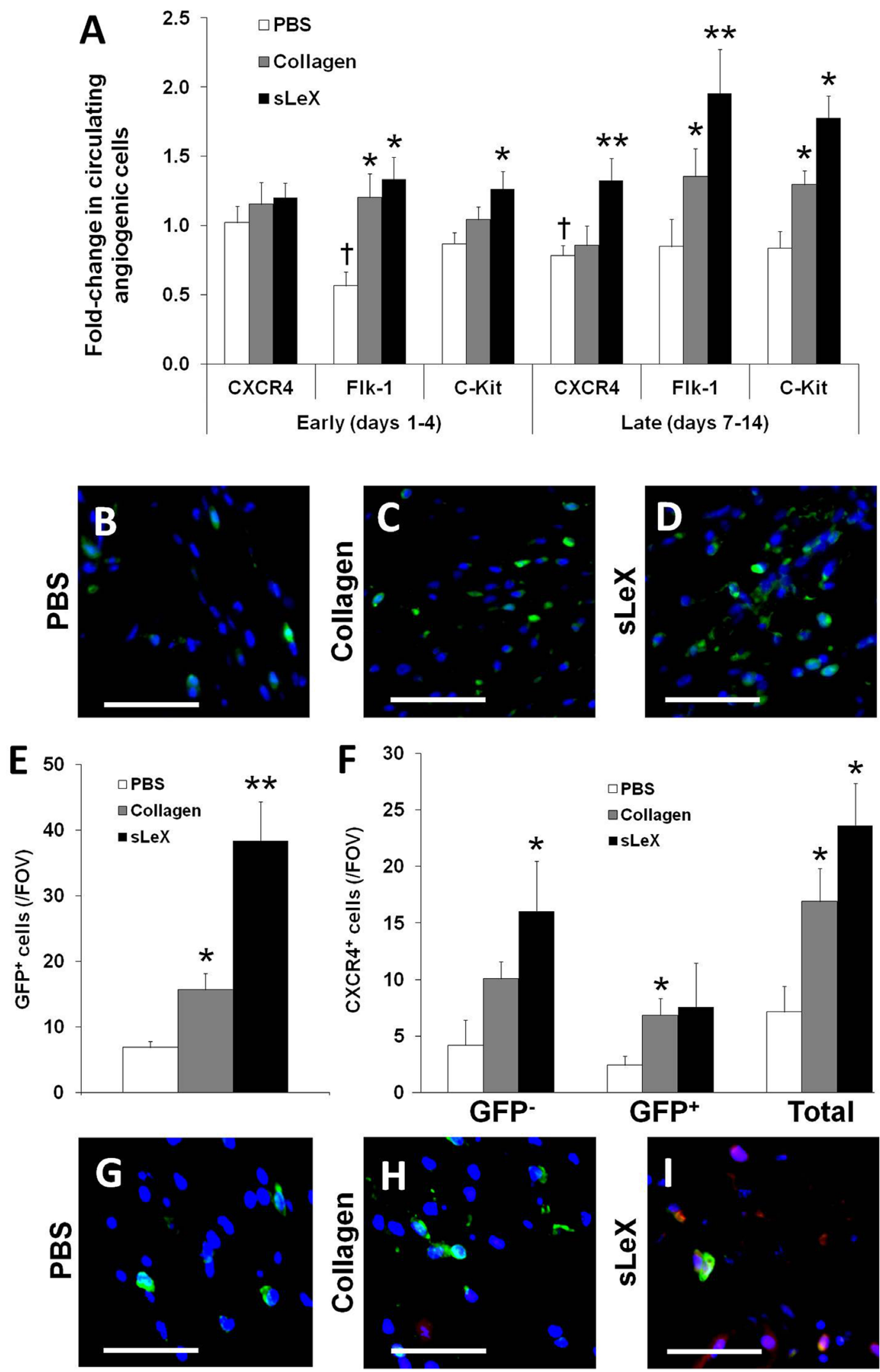

Fig. 7. Mobilisation and recruitment of bone marrow CACs and local cells are improved by sLe $\mathrm{e}^{\mathrm{X}}$-matrix treatment. (A) Levels of $\mathrm{GFP}^{+}$circulating cells (relative to day 0 baseline) expressing CXCR4, flk-1 and c-kit measured by flow cytometry at 1-4 and 7-14 days after treatment with PBS, collagen or sLe ${ }^{\mathrm{X}}$-matrix. (B-D) Double immunostaining of hind-limb muscle for recruited $\mathrm{GFP}^{+}$marrow cells (green) and nuclei (DAPI). (E) Numbers of GFP ${ }^{+}$cells per FOV in hind-limb muscle. (F) Numbers of local (GFP), marrow $\left(\mathrm{GFP}^{+}\right)$, and total CXCR4 ${ }^{+}$cells per FOV in hind-limb muscle. (G-I) Triple immunostaining of hind-limb muscle for recruited GFP ${ }^{+}$marrow cells (green), CXCR4 (red) and nuclei (DAPI). Scale bars $=50 \mu \mathrm{m}$. ${ }^{*} p<0.05 v s$. PBS; ${ }^{* *} p<0.05 v s$. all others; ${ }^{\dagger} p<0.05 v s$. baseline. Results represent data from $n=8-9$ separate mice per group. 


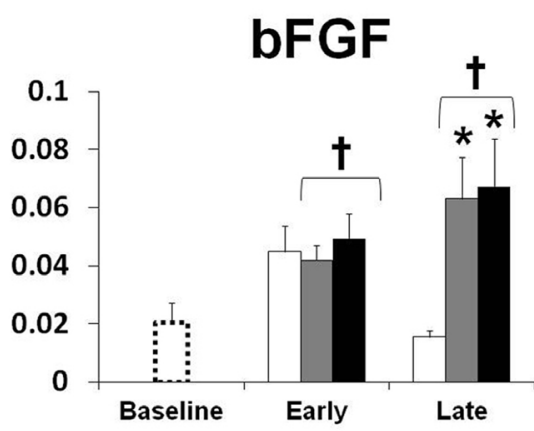

IGF-1
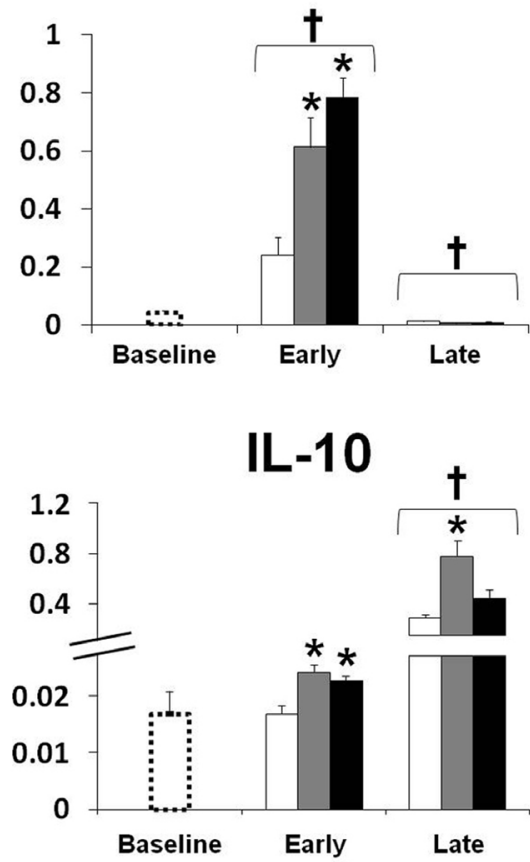

L-selectin

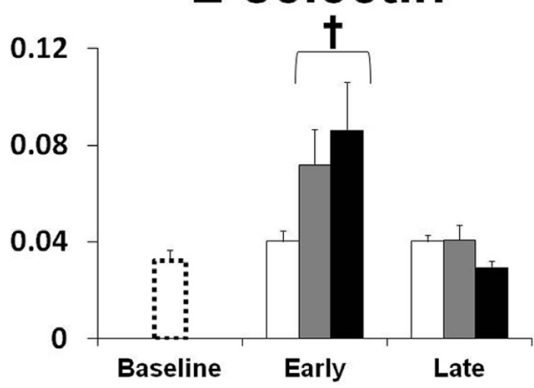

TIMP-2

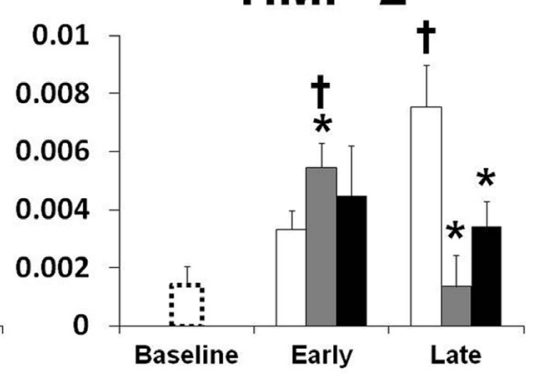

IGFBP-2

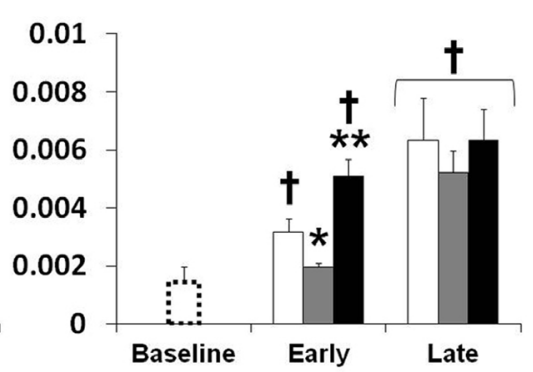

SDF-1 $\alpha$

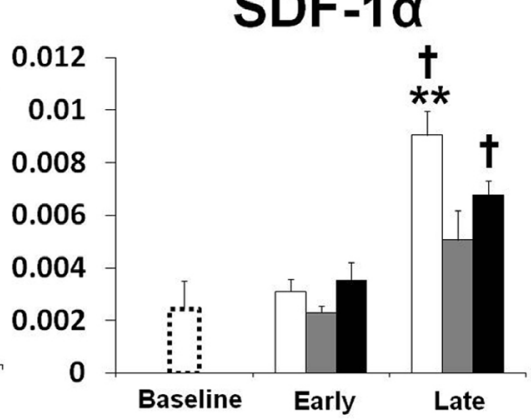

P-selectin

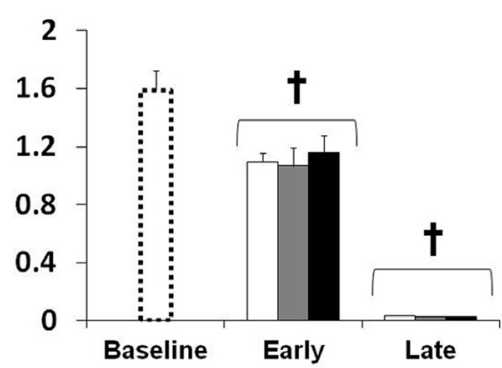

VCAM-1

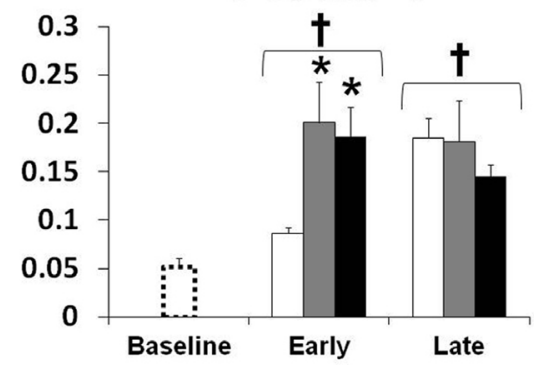

IGFBP-5

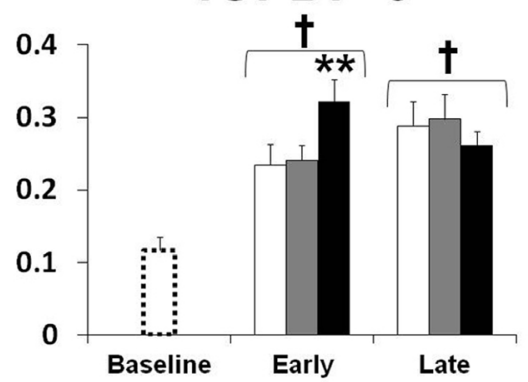

VEGF

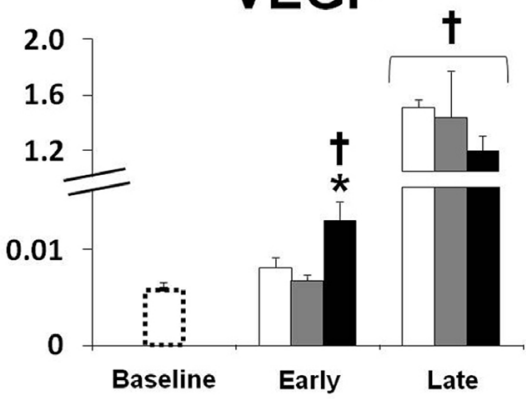

TNF $\alpha$

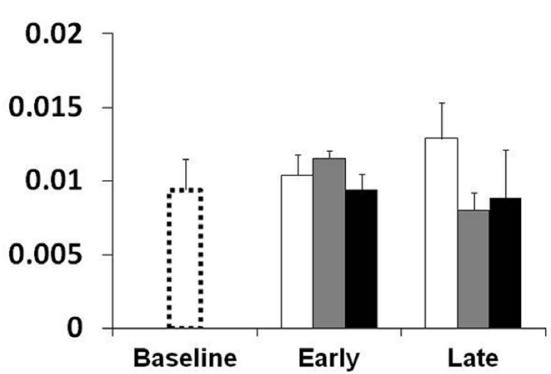

\section{Legend \\ $\square$ PBS \\ $\square$ Collagen \\ sLeX}

Fig. 8. Matrix treatment augments the protein levels of regenerative cytokines in ischaemic hind-limb muscle. Histograms represent protein levels of cytokines, relative to baseline controls (animals that did not receive ligation surgery or treatment) in hind-limb muscle tissue samples at 3 and 10 days after treatment with PBS, collagen or sLe $\mathrm{X}_{-}$ matrix (non-BMTx model). Pro-vasculogenic (bFGF, TIMP-2, VCAM-1, VEGF), pro-myogenic (IGF-I, IGFBP-2, IGFBP-5), chemotactic (SDF-1 $\alpha$, VEGF) and immunomodulatory (IL-10, L-Selectin, P-Selectin, TNF $\alpha$ ) cytokines were evaluated. The y-axis for all graphs represents arbitrary chemiluminescence units. ${ }^{\dagger} p<0.05 v$. baseline; ${ }^{*} p<0.05$ $v s$. PBS; ${ }^{* *} p<0.05$ vs. all others at the indicated time point. Histograms represent data $n=5$ different mice per group per time point. 

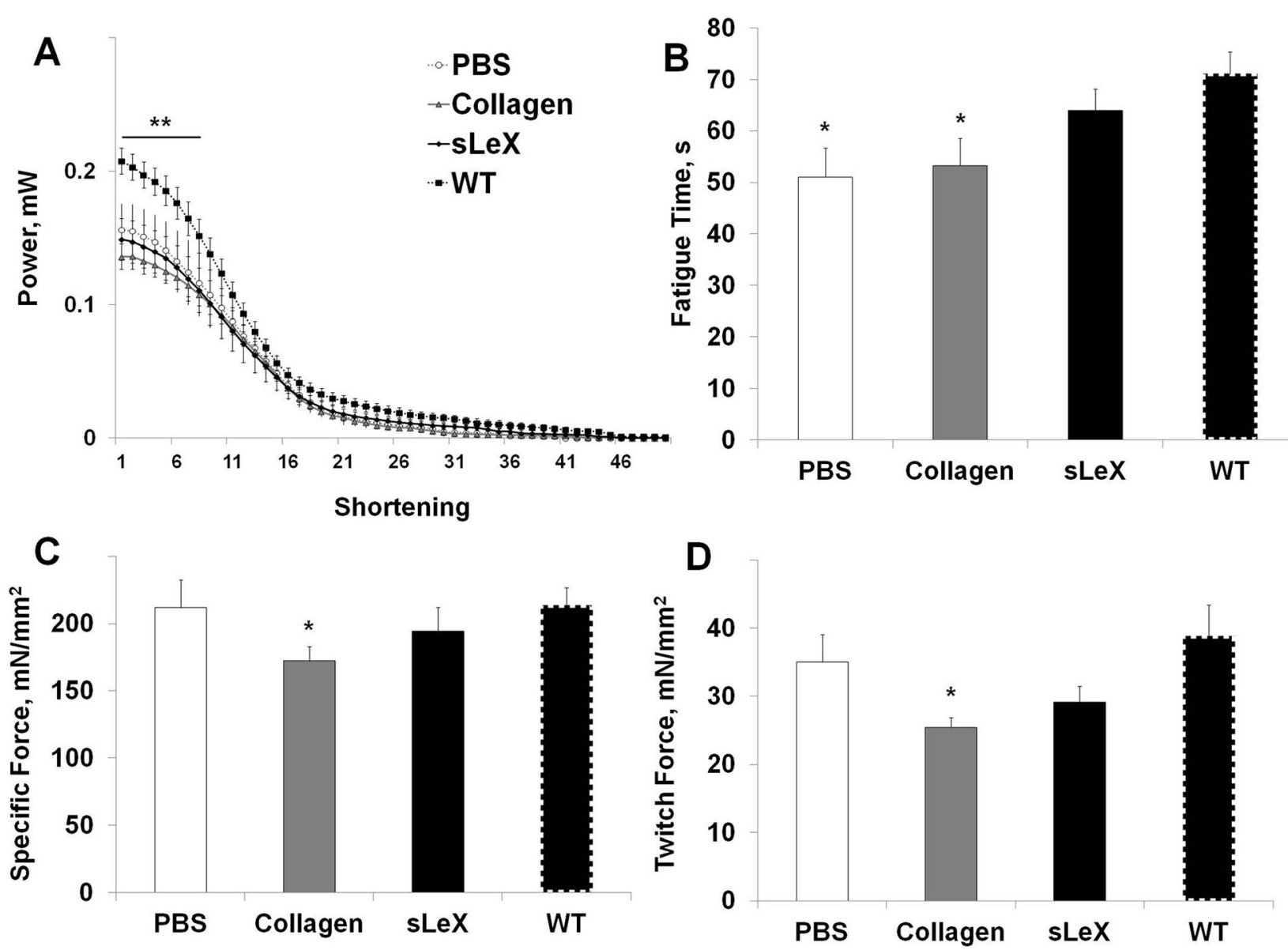

Fig. 9. Ex vivo analysis of explanted soleus muscle function. Power was reduced in all ligated soleus muscles, compared to wild-type controls (A). Time to fatigue was unaffected with sLe ${ }^{\mathrm{X}}$-matrix treatment, but reduced in PBS controls and collagen matrix treatment $(\mathbf{B})$. Specific force $(\mathbf{C})$ and specific twitch force $(\mathbf{D})$ were reduced with collagen matrix treatment. ${ }^{*} p \leq 0.03 v s$. wild-type; ${ }^{* *} p<0.05$ for wild-type $v s$. all other treatments.

Matrix treatment increases marrow-derived and local $\mathrm{CXCR}^{+}$cell recruitment to the ischaemic hindlimb

Following bone marrow cell mobilisation into the circulation, we investigated the effect of the different treatments on recruiting mobilised $\mathrm{GFP}^{+}$cells from the circulation to the ischaemic hind-limb muscle. After 2 weeks, the $\mathrm{sLe}^{\mathrm{x}}$-matrix treatment resulted in the greatest recruitment and engraftment of bone marrow cells in the hind-limb muscle, which was 5.6- $(p=0.004)$ and 2.5 -fold $(p=0.02)$ more than the PBS and collagen matrix treatments, respectively (Fig. 7B-E). The collagen matrix also increased the number of engrafted $\mathrm{GFP}^{+}$ cells by 2.3 -fold ( $p=0.02$ ), compared to PBS (Fig. 7E). Immunostaining did not demonstrate any $\mathrm{GFP}^{+}$cell incorporation into vasculature, nor into myocytes.

The importance of CXCR4 expression for neovascularisation has been previously shown (Grounds, 2008; Seeger et al., 2009; Borselli et al., 2010); therefore, we sought to characterise $\mathrm{CXCR}^{+}$cells in the present study. Both sLe ${ }^{\mathrm{X}}$-matrix and collagen matrix treatments increased total counts of $\mathrm{CXCR} 4^{+}$cells in treated hindlimbs compared to PBS (Fig. 7F-I), by 3.3- $(p=0.002)$ and 2.4-fold ( $p=0.03)$, respectively. Notably, the $\mathrm{sLe}^{\mathrm{x}}$ matrix recruited more non-marrow derived CXCR4 ${ }^{+}$cells (by 9.2-fold; likely from the local tissue since they lack GFP expression), compared to the PBS group ( $p=0.02)$. Therefore, recruitment/engraftment of both bone marrowderived CACs and local angiogenic cells were greatest with the $\mathrm{sLe}^{\mathrm{X}}$-matrix treatment.

\section{Matrix treatments augment protein levels of regenerative factors and cytokines}

To explore potential mechanisms for the observed myogenic and vascular regeneration, we used a mousespecific antibody array to assess protein levels of cytokines in the ischaemic tissue in the non-BMTx model. A summary of differences in the levels of various cytokines in the hind-limb is presented in Fig. 8 (differences with $p<0.05$ are indicated). Animals that received neither the ligation surgery nor an injected treatment served as baseline controls. Myogenic-mediated factors assessed included IGF- 1 and IGFBPs. At day 3, the sLe ${ }^{\mathrm{X}}$-matrix greatly increased local IGF-1 (17.9-fold vs. baseline). Similarly, IGFBP-2 and -5 levels were increased with $\mathrm{sLe}^{\mathrm{x}}$-matrix treatment $v s$. all other treatments at the early time point ( $\geq 2.1$ - and $\geq 1.4$-fold, respectively).

In the analysis of angiogenic cytokines, notably, only the $\mathrm{sLe}^{\mathrm{X}}$-matrix treatment increased hind-limb VEGF levels (2.3-fold $v s$. baseline; $\geq 1$.8-fold $v s$. other treatments). In 

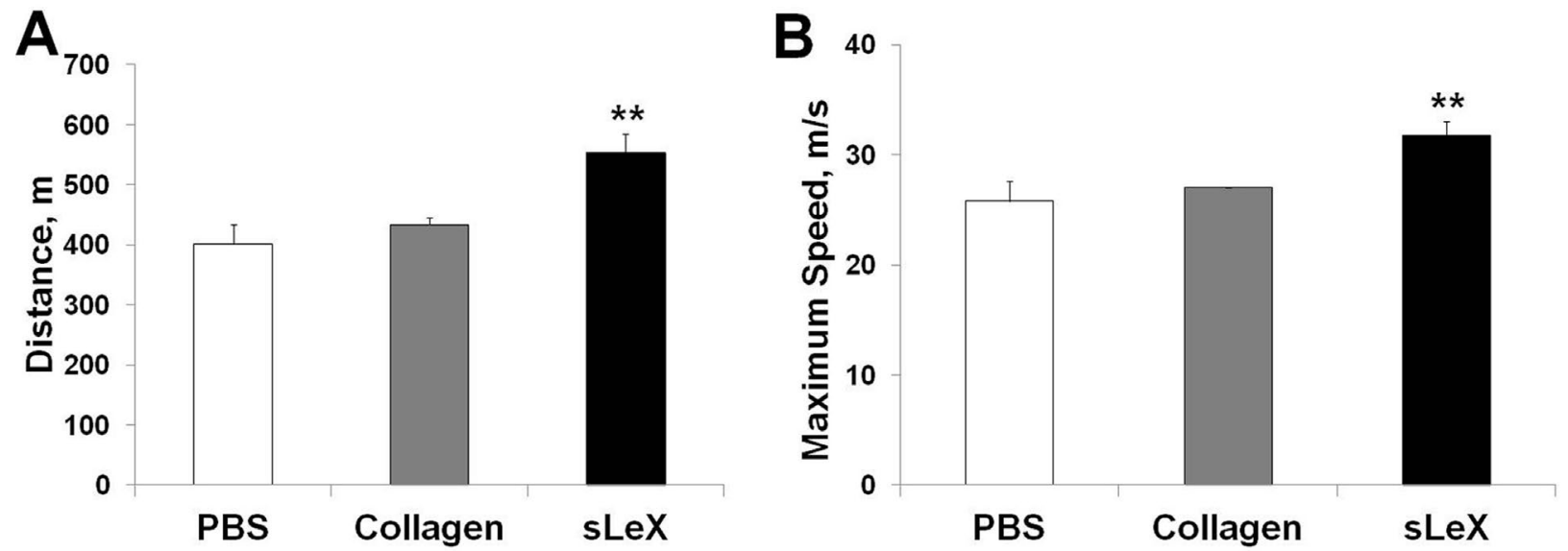

Fig. 10. sLe $^{\mathrm{x}}$-enhanced matrix allows for functional recovery in a unilateral model of hind-limb ischaemia. When forced to run on a treadmill, animals treated with $\operatorname{sLe}^{\mathrm{x}}$-matrix ran significantly further $(\mathbf{A} ; p \leq 0.009)$ and at greater speeds $(\mathbf{B} ; p \leq 0.02)$ than PBS- or collagen matrix-treated animals.

addition, bFGF was upregulated in both matrix treatments early on (vs. baseline at day 3 ), and this upregulation was maintained later on ( $v s$. baseline and $\geq 4$.2-fold $v s$. PBS at day 10). VCAM-1 was increased for all treatments at the 3- and 10-day time point; however, matrix treatments increased VCAM-1 levels by $\geq 2.2$-fold $v s$. PBS early on (day 3). At 10 days, only limbs treated with PBS had a lasting increase in the anti-angiogenic and anti-remodelling protein TIMP-2 (5.4-fold $v s$. baseline). Matrices promoted greater levels of IL-10 (anti-inflammatory cytokine) in the ischaemic muscle (by $\geq 1.8$-fold), compared to PBSinjected hind-limbs. Overall, both matrices increased local anti-inflammatory and angiogenic cytokines, but the sLe ${ }^{\mathrm{X}}$ matrix treatment had the most profound effect of increasing both myogenic and vasculogenic cytokine production.

\section{Matrix treatment affects muscle function}

For the first 8 shortenings, soleus power was reduced in all treated animals, compared to wild-type $(p<0.05$; Fig. 9A). The soleus muscle from PBS- and collagen matrix-treated mice fatigued more rapidly than wildtype soleus $(51.0 \pm 5.7 \mathrm{~s}$ and $53.3 \pm 5.4 \mathrm{~s}$ vs. $71.2 \pm 4.2 \mathrm{~s}$, respectively; $p \leq 0.03$; Fig. 9B), whereas no difference in the time to fatigue was observed in $\mathrm{sLe}^{\mathrm{X}}$-matrix-treated muscles $(64.0 \pm 4.1 \mathrm{~s})$ compared to wild-type controls. Only treatment with the collagen matrix changed the soleus twitch and specific forces compared to wild-type controls; specific force was reduced $(172.1 \pm 10.8 \mathrm{vs}$. $214.0 \pm 12.7 \mathrm{mM} ; p=0.03$; Fig. 9C) and twitch force was reduced $\left(25.4 \pm 1.4\right.$ vs. $38.9 \pm 4.5 \mathrm{mM} / \mathrm{mm}^{2} ; p=0.01$; Fig. 9D). The sLe ${ }^{\mathrm{X}}$-matrix-treated muscles only trended towards a reduction in twitch force ( $p=0.1$; Fig. 9D).

\section{The sLe ${ }^{\mathrm{x}}$-matrix ultimately supports in vivo functional recovery}

The sLe ${ }^{\mathrm{X}}$-matrix-treated mice that were forced to run until exhaustion were able to run significantly greater lengths, compared to PBS- and collagen matrix-treated animals (553 m vs. $401 \mathrm{~m}$ and $433 \mathrm{~m}$, respectively; $p \leq 0.009$; Fig. 10A). Exhaustion also occurred at higher speeds for $\mathrm{sLe}^{\mathrm{x}}$ matrix-treated mice $(31.8 \mathrm{~m} / \mathrm{s})$ vs. PBS- $(25.8 \mathrm{~m} / \mathrm{s})$ and collagen matrix-treated $(27 \mathrm{~m} / \mathrm{s})$ animals $(p \leq 0.02$; Fig.
10B). Differences in running abilities were not observed between PBS and collagen matrix treatments.

\section{Discussion}

The need for biomaterials to act as de novo environments in vivo for stem cell and regenerative responses has been identified (Rossi et al., 2010; Kuraitis et al., 2012). In the present study, we demonstrated that the treatment of hind-limb ischaemia with a sLe ${ }^{\mathrm{X}}$-collagen matrix can augment bone marrow and local cell responses, to improve neovascularisation and regenerative myogenesis of skeletal muscle. Notably, the $\mathrm{sLe}^{\mathrm{X}}$-matrix demonstrated an inherent ability to: (1) physically mimic skeletal muscle; (2) augment pluripotent mESC differentiation towards a muscle lineage; (3) stimulate skeletal muscle regeneration; (4) augment the mobilisation and recruitment of marrowderived progenitor cells; and (5) regulate the temporal expression of cytokines involved in both the muscular and vascular regenerative processes.

The culture of mESCs on our materials as a substrate resulted in increased differentiation towards a myogenic lineage compared to the standard ESC-to-myocyte culture protocol (which uses TCPS). ESC cultures were performed to assess the matrices' inherent ability to guide pluripotent progenitors towards a myocytic lineage. At day 15, mESCs cultured on matrices expressed greater levels of Pax3 and Pax7 (myogenic progenitor marker), Myf5 and myogenin (MRFs), and MHC3 (final muscle differentiation marker) versus culture on TCPS. Therefore, culture on the matrices promoted a more efficient differentiation pathway in $\mathrm{mESCs}$ that produced a premyogenic progenitor population, and enhanced MRF expression and terminal differentiation. Given that ESCs are pluripotent and have the capacity to differentiate into cells of any lineage (Guan et al., 1999), it is significant that the collagen-based matrix appears to have an inherent ability to direct mESC differentiation towards a Pax $3 / 7^{+v e}$ progenitor population and skeletal myogenesis. The generation of $\mathrm{Pax} 3 / 7^{+v e}$ muscle progenitor cells is noteworthy, as these cells would be valuable in replenishing the satellite cell niche (Montarras et al., 2005; 
Kuang et al., 2007) in therapies targeted at treating muscle diseases, and Pax3/7 induce skeletal myogenesis in stem cells (Ridgeway and Skerjanc, 2001; Seale et al., 2004). These results suggest that the collagen-based matrices could serve a two-fold purpose: (1) to provide an injectable biomaterial for the promotion of endogenous regenerative myogenesis; and (2) to enhance and enrich populations of myogenic lineage cells for transplantation.

It is known that mechanical properties of a cell's extracellular environment, and in particular the elasticity of the cell's substrate, are key regulating factors in the differentiation of cells (Engler et al., 2006). Ex vivo, cells appear to differentiate towards phenotypes that would naturally be found on similar substrates, such as neural differentiation on very soft materials and osteogenic differentiation on very hard materials. A substrate with an elastic modulus range of $6.5-17 \mathrm{kPa}$ appears ideal for maximal myotube differentiation (Engler et al., 2004). Similarly, a range of $8-17 \mathrm{kPa}$ induces a myoblast-like morphology in mesenchymal stem cells and a marked increase in the myogenic transcription factor MyoD (Engler et al., 2006). Unstimulated skeletal muscle has a range of $10-20 \mathrm{kPa}$ (Engler et al., 2006). Although these examples used atomic force microscopy, which may overestimate the moduli values, the elasticity values of our matrices (5.85 and $7.51 \mathrm{kPa}$ ) obtained using compression testing are quite similar. This suggests that the matrices' elasticity may play a role in the observed myogenesis. Furthermore, the statistical difference between matrices' elastic moduli may be one of the key reasons for the increased emergence of myocytic lineages on the $\mathrm{sLe}^{\mathrm{X}}$-matrix. It is not likely that the matrices' rheological properties contributed to the observed differences in myogenesis, since viscosity and time to gelation between the two materials were very similar. However, the addition of $\mathrm{sLe}^{\mathrm{X}}$ to the collagen matrix made regions of the material less hydrophilic. The degree of hydrophilicity is another key property for cell interaction, as slight changes in a material's hydrophilicity have been shown to have dramatic effects on cellular adhesion and spreading (Elliott et al., 2007; Derkaoui et al., 2010), and this may be involved in the observed differences in mESC phenotypes.

Pelosi et al. have demonstrated that in wild-type mice, the onset of skeletal muscle regeneration begins around 10 days after injury (Pelosi et al., 2007). In the present study, at 3 days post-treatment, very few regenerating fibres were apparent and we observed no differences between treatments. However, at day 10 , mice treated with $\mathrm{sLe}^{\mathrm{x}}$ matrix displayed an increase in the number of regenerating fibres, and the same effect was observed at 14 days in the BMTx model. In parallel, the $\mathrm{SLe}^{\mathrm{X}}$-matrix did not increase the hind-limb levels of myogenic mRNA transcripts at day 3 , but at day 10 it had induced an upregulation of transcripts of genes that are known to have active roles in directing myogenesis, such as M-cadherin (Donalies et al., 1991), Myf5 (Rudnicki et al., 1993; Gayraud-Morel et al., 2007), MyoD (Rudnicki et al., 1993), myogenin (Nabeshima et al., 1993), Pax7 (McGeachie and Grounds, 1987) and Six1 (Liu et al., 2010). Interestingly, animals receiving the PBS control demonstrated a greater abundance of Pax 7 transcripts at day 3, compared to both matrices.
Pax7 is indicative of skeletal precursor satellite cells, and after injury, the normal response for satellite cells is to synthesise new DNA and proliferate after $18 \mathrm{~h}$, peaking at 3 days and gradually reducing afterwards (McGeachie and Grounds, 1987). Our results suggest that PBS-treated animals experienced this phenomenon, and that matrix treatment may have delayed it. Despite this delay, the $\mathrm{sLe}^{\mathrm{X}}$ matrix was superior in inducing regenerative myogenesis over the longer term.

In our previous report, we noted that the $\mathrm{sLe}^{\mathrm{x}}$-matrix could increase the number of CACs in the circulation (Suuronen et al., 2009). In the present study, using a $\mathrm{GFP}^{+}$marrow transplant and hind-limb ischaemia model, we demonstrated that $\mathrm{c}-\mathrm{kit}^{+}$, flk- $1^{+}$and $\mathrm{CXCR} 4^{+} \mathrm{CACs}$ were increased in animals with $\mathrm{sLe}^{\mathrm{x}}$-matrix-treated hindlimbs at early time points (days 1-4) after treatment. The circulating cells analysed were positive for GFP expression, indicating bone marrow origin of the responding cells. Greater numbers of these cells persisted in the circulation of $\mathrm{sLe}^{\mathrm{X}}$-matrix-treated animals by 2 weeks post-application.

The analysis of hind-limb tissue sections revealed that the $\mathrm{sLe}^{\mathrm{X}}$-matrix was superior at recruiting marrow-derived $\left(\mathrm{GFP}^{+}\right)$and $\mathrm{CXCR}^{+}$cells to the treated muscle tissue. Notably, the number of $\mathrm{CXCR}^{+}$cells of non-marrow origin $\left(\mathrm{GFP}^{-}\right)$was greater in hind-limbs treated with $\mathrm{sLe}^{\mathrm{X}}$ matrix than in the other groups, suggestive of an enhanced local cell response with this treatment. It is well-known that marrow-derived CACs are therapeutic and may augment reperfusion (Abdel-Latif et al., 2007). Recently, the role of $\mathrm{CXCR}^{+}$fractions of CACs has been highlighted (Seeger et al., 2009): compared to CXCR4- fractions, $\mathrm{CXCR}^{+}$cells display a more potent ability to migrate, as well as a superior ability to augment neovascularisation and to secrete pro-vasculogenic cytokines. This suggests that $\mathrm{CXCR}^{+}$cells are a highly therapeutic fraction of CACs with a strong homing ability, which is particularly important in the response to ischaemic damage and support of neovascularisation.

By 2 weeks, the $\mathrm{sLe}^{\mathrm{X}}$-matrix improved the perfusion of ischaemic hind-limbs compared to PBS and collagen matrix treatments, although both matrices increased hindlimb arteriole density to similar levels. In contrast, we have previously observed increased arteriole density with $\mathrm{sLe}^{\mathrm{x}}$ matrix compared to collagen matrix treatment (Suuronen et al., 2009). Despite being another hind-limb ischaemia model, there were key differences between the current study and our 2009 study that may have altered the physiological responses to the material's application: rat versus mouse model; BMTx versus non-BMTx; young (rats) versus older (mice). In this study, the $\mathrm{sLe}^{\mathrm{X}}$-matrix was able to induce the formation of arterioles of greater size, possibly contributing to greater blood flow. This may be indicative of more mature and/or strengthened arterioles, since the size (cross-sectional area) in newly developing vasculature was recently shown to increase over time, up to a period of 4 weeks (Ruvinov et al., 2011). The differentiation of GFP ${ }^{+}$ marrow-derived cells into cells of the vasculature was not observed. The differentiation of CACs into vascular cells is a topic of intense debate (Klein et al., 2010) and the potential for vascular transdifferentiation of CACs is not yet clear. It is more likely that the increased engraftment of 
$\mathrm{GFP}^{+}$marrow cells in the $\mathrm{sLe}^{\mathrm{x}}$-matrix treated hind-limbs contributes to a greater paracrine mechanism (higher levels of angiogenic cytokines were observed), which then induces a superior local cell response (supported by the observation that greater numbers of non-marrow derived $\left(\mathrm{GFP}^{-}\right) \mathrm{CXCR}^{+}$cells were present in $\mathrm{sLe}^{\mathrm{x}}$-matrix treated muscle). Furthermore, it was recently highlighted that the expression of L-selectin (the receptor for $\mathrm{sLe}^{\mathrm{X}}$ ) greatly enhances the in vivo migration and retention of transplanted cells into ischaemic myocardium (Bernal et al., 2011). Therefore, the presentation of $\mathrm{sLe}^{\mathrm{X}}$ may also contribute to the retention of therapeutic cells in the ischaemic muscle.

A time course analysis of cytokines indicated the simultaneous signalling for vascular and muscular regeneration and also corroborated the myogenic and vasculogenic results that were observed. IGF-1, a potent initiator of skeletal myogenesis (Pelosi et al., 2007), displayed the greatest increase with $\mathrm{sLe}^{\mathrm{X}}$-matrix treatment at day 3 post-treatment. Similarly, an increase in IGF binding proteins IGFBP- 2 and -5 , in response to $\mathrm{SLe}^{\mathrm{X}}$ matrix treatment, was observed only at the 3 day time point. The family of IGFBPs (1 through 5) have implicated and overlapping roles in regulating myogenesis (Duan et al., 2010); however, a knock-out of multiple members has shown reduced skeletal muscle size, implicating their role in the growth and homeostasis of skeletal muscle (Ning et al., 2006). IGFBP-5 is perhaps the most potent family member for myogenesis. Its expression increases greatly in differentiating myoblasts (Bayol et al., 2000) and in the presence of IGF-1, it can augment the myogenic actions of IGF-1, indicated by greater myogenin expression and fusion of myoblasts into myotubes (Ewton et al., 1998; Musaro and Rosenthal, 1999). Vasculogenic cytokines were also assessed. The matrix-induced production of bFGF, a molecule able to stimulate reperfusion of ischaemic muscle (Boodhwani et al., 2008), was observed at the same time when matrices demonstrated improved perfusion, while concurrently, the level of an inhibitor of angiogenesis, TIMP-2 (Koike et al., 2003), was reduced. Another indicator of neovascularisation, VCAM-1 (Martin et al., 2005), was also increased with matrix treatment. Together, with the transcriptional and morphological evidence of myogenesis, it is believed that $\mathrm{sLe}^{\mathrm{x}}$-matrix induced local paracrine signalling, which is responsible for the later initiation of regenerative events that manifest as amplified vasculogenesis, followed by myogenesis, at around 10 days. This concept is supported by findings which demonstrate that when vascularisation is present, there is a greater functional enhancement of regenerating muscle (Koffler et al., 2011).

PBS treatment led to the greatest local level of SDF-1 (at the late time-point), a chemoattractant for CXCR4expressing cells. Interestingly, more $\mathrm{CXCR}^{+}$cells were observed in the circulation and engrafted into muscle after matrix treatment, despite the greater concentration of SDF-1 in the PBS-treated hind-limbs (at 10 days). Greater levels of SDF-1 were expected with matrix treatment; however, serum SDF-1 levels were not measured. If elevated, serum SDF-1 could explain the increase in mobilised and engrafted $\mathrm{CXCR} 4^{+} \mathrm{CPCs}$ in matrix-treated tissue. Furthermore, local SDF-1 expression in response to ischaemic injury is maintained over longer periods in older mice ( $\sim 18$ months) compared to the response in younger mice (3 months), which peaks at day 3 (Wang et al., 2011). This suggests that increased SDF-1 levels may persist in tissue that is less efficient at recovering from perfusion defects; under this scenario, the PBS-treated hind-limb muscle, in which perfusion was not restored, would maintain an elevated local SDF-1 concentration compared to the re-perfused matrix-treated hind-limbs. Also, SDF-1-CXCR4 responses may not be linear, whereby a threshold concentration of SDF-1 is reached, resulting in a plateau of the CXCR4 response (Kimura and Tabata, 2010), and therefore the elevated SDF-1 levels seen with PBS treatment may be ineffective at activating CXCR4 ${ }^{+}$ cells over the long-term. Other chemokines, such as VEGF, were upregulated with sLe ${ }^{\mathrm{x}}$-matrix treatment. When VEGF, known as a progenitor cell activator and homing factor, and as an angiogenic cytokine, is produced locally by transplanted muscle-derived stem cells, enhanced myogenesis occurs in addition to increased angiogenesis (Deasy et al., 2009), underscoring the importance and role of local VEGF production in injured muscle. Furthermore, both matrix treatments augmented the level of IL-10, a known cytoprotective cytokine that is endogenously upregulated after an ischaemic episode (Hayward et al., 1997; Frangogiannis et al., 2000). IL-10 has also recently been associated with improved muscle regeneration, based on its ability to inhibit the cytotoxic M1 macrophage phenotype (Villalta et al., 2011). We assessed the potential of these materials to elicit a harmful inflammatory response by monitoring TNF- $\alpha$. Similar to our previous study, the matrix application did not induce TNF- $\alpha$ expression (Suuronen et al., 2009), highlighting the material's biocompatibility.

It is known that ischaemic injury reduces the maximal forces in soleus muscle (Vignaud et al., 2010) and that this leads to fibre death and subsequent regeneration. Power measurements showed that all ischaemic solei were less efficient; however, the small changes in maximal (specific and twitch) forces observed in our model were surprising, but perhaps attributable to the relatively mild degree of ischaemia that was induced. Statistically, both matrix treatments reduced specific maximal forces, but the reductions observed with $\mathrm{sLe}^{\mathrm{X}}$-matrix were less severe when compared to control animals. Despite these reductions in matrix-treated solei, it has been shown that regenerating soleus muscle exhibits reduced maximal forces, compared to soleus in a non-regenerative state (Esposito et al., 2007), suggesting regeneration is occurring in matrix-treated muscles. Given that ischaemic injury initiates major changes in ECM composition (Roy et al., 2006), together with the observed changes in ECMmodulating proteins in this study and others (Suuronen et al., 2009; Kuraitis et al., 2011b), we believe that muscle regeneration and ECM turnover leads to the observation of reduced maximal forces. Moreover, the reduction in specific force is probably due to the fact that the matrix increases the number of regenerating fibres, which do not contribute to force generation. We can envision that the regenerating fibres, once they complete the maturation program, will significantly contribute to an increase in 
muscle strength. Despite the loss of force, this did not translate into reduced function in vivo for mice with ischaemic hind-limbs treated with $\mathrm{sLe}^{\mathrm{X}}$-matrix, which experienced improved mobility (ran further and faster on a treadmill). Arguably the most important parameter measured, $\mathrm{sLe}^{\mathrm{x}}$-matrix treatment allowed for functional restoration of ischaemic hind-limbs. This result was supported by the ex vivo observation that $\mathrm{sLe}^{\mathrm{X}}$-matrix treatment improved muscle endurance, compared to both PBS- and collagen matrix-treated muscle, which reached fatigue sooner. Furthermore, these functional benefits were observed in ischaemic soleus muscles, which are distal to the injury/treatment site (gastrocnemius muscle), highlighting the potential of the matrix to mediate vascular and muscle regeneration beyond the site of application.

In order to achieve maximal recovery of skeletal muscle from ischaemic injury, the formation of new vessels is a requirement before the regeneration of myocytes will occur (Ko et al., 2007; Grounds, 2008). Experimentally, it has been demonstrated that skeletal myogenesis is correlated with vascular regeneration after stem cell transplantation (Shi et al., 2009). Our study also shows that while two matrix treatments both induce relatively similar amounts of myogenesis, the treatment with superior vasculogenesis ( $\mathrm{sLe}^{\mathrm{x}}$-matrix) is the only one to lead to functional recovery in ischaemic hind-limbs. One study has used an injectable alginate scaffold to release multiple regenerative growth factors in an attempt to restore skeletal muscle after ischaemic injury (Borselli et al., 2010). Although a combined result of muscle and vascular regeneration occurred, the outcome depended greatly on the ability of the materials/releasing systems to function properly and this function is difficult to assess in vivo. Growth factor delivery strategies face various biological, engineering and technical limitations (Chen et al., 2010), such as loss of bioactivity, insufficient gradients and rapid cytokine depletion. Our results present an efficacious method of restoring both muscular and vascular profiles of skeletal muscle, overcoming the potential limitations that have been associated with material functionality after implantation.

\section{Conclusions}

We have presented evidence for the reperfusion and both phenotypic and functional regeneration of muscle damaged from an ischaemic event after the application of a sialyl Lewis ${ }^{\mathrm{x}}$-enhanced injectable collagen matrix. Based on its mechanical properties and its ability to guide pluripotent cells towards a myogenic lineage, we believe that this injectable matrix has an inherent ability to support muscle regeneration. Considering the limited success of regenerative stem cell transplantation, the need for cell-free methods of regeneration may be necessary, and the non-invasive application of biocompatible, naturally derived materials that can augment neovascularisation and myogenesis holds great promise as a future therapy for prevalent myopathies.

\section{Acknowledgments}

The authors would like to thank Carmine Nicoletti, Elaine Wong and Suzanne Crowe for their technical assistance, and Dr. Wankei Wan for the use of his mechanical testing facilities at the Fordham Centre for Biomedical Engineering, University of Western Ontario, Canada. This work was supported by grant-in-aid \#T-6793 from the Heart \& Stroke Foundation of Ontario (to EJS), by grants from the 7FP-Myoage, Fondazione Roma, and AFM (to AM) and by operating grant \#84458 from the Canadian Institutes of Health Research (to ISS). DK was supported by a Canadian Institutes of Health Research Canadian Graduate Scholarship, DE was supported by a National Sciences and Engineering Research Council Alexander Graham Bell Award, PZ was supported by the Lawrence Soloway Research Fellowship award, DTP was supported by a University of Ottawa Cardiology Research Endowment Fellowship, KM was supported by an Ontario Graduate Scholarship, and DK and TS were supported by Heart and Stroke Foundation of Ontario Master's Awards.

\section{References}

Abdel-LatifA, Bolli R, Tleyjeh IM, Montori VM, Perin EC, Hornung CA, Zuba-Surma EK, Al-Mallah M, Dawn B (2007) Adult bone marrow-derived cells for cardiac repair: a systematic review and meta-analysis. Arch Intern Med 167: 989-997.

Bayol S, Loughna PT, Brownson C (2000) Phenotypic expression of IGF binding protein transcripts in muscle, in vitro and in vivo. Biochem Biophys Res Commun 273: 282-286.

Bernal A, San Martin N, Fernandez M, Covarello D, Molla F, Soldo A, Latini R, Cossu G, Galvez BG (2011) L-selectin and SDF-1 enhance the migration of mouse and human cardiac mesoangioblasts. Cell Death Differ 19: 345-355.

Biancone L, Cantaluppi V, Duo D, Deregibus MC, Torre C, Camussi G (2004) Role of L-selectin in the vascular homing of peripheral blood-derived endothelial progenitor cells. J Immunol 173: 5268-5274.

Boodhwani M, Voisine P, Ruel M, Sodha NR, Feng J, Xu SH, Bianchi C, Sellke FW (2008) Comparison of vascular endothelial growth factor and fibroblast growth factor-2 in a swine model of endothelial dysfunction. Eur J Cardiothorac Surg 33: 645-650.

Borselli C, Storrie H, Benesch-Lee F, Shvartsman D, Cezar C, Lichtman JW, Vandenburgh HH, Mooney DJ (2010) Functional muscle regeneration with combined delivery of angiogenesis and myogenesis factors. Proc Natl Acad Sci U S A 107: 3287-3292.

Carosio S, Berardinelli MG, Aucello M, Musaro A (2011) Impact of ageing on muscle cell regeneration. Ageing Res Rev 10: 35-42.

Chen FM, Zhang M, Wu ZF (2010) Toward delivery of multiple growth factors in tissue engineering. Biomaterials 31: 6279-6308. 
Corti S, Nizzardo M, Nardini M, Donadoni C, Salani S, Ronchi D, Simone C, Falcone M, Papadimitriou D, Locatelli F, Mezzina N, Gianni F, Bresolin N, Comi GP (2010) Embryonic stem cell-derived neural stem cells improve spinal muscular atrophy phenotype in mice. Brain 133: 465-481.

Deasy BM, Feduska JM, Payne TR, Li Y, Ambrosio F, Huard J (2009) Effect of VEGF on the regenerative capacity of muscle stem cells in dystrophic skeletal muscle. Mol Ther 17: 1788-1798.

Del Prete Z, Musaro A, Rizzuto E (2008) Measuring mechanical properties, including isotonic fatigue, of fast and slow MLC/mIgf-1 transgenic skeletal muscle. Ann Biomed Eng 36: 1281-1290.

Deng C, Zhang P, Vulesevic B, Kuraitis D, Li F, Yang AF, Griffith M, Ruel M, Suuronen EJ (2010) A collagenchitosan hydrogel for endothelial differentiation and angiogenesis. Tissue Eng Part A 16: 3099-3109.

Derkaoui SM, Labbe A, Purnama A, Gueguen V, Barbaud C, Avramoglou T, Letourneur D (2010) Films of dextran-graft-polybutylmethacrylate to enhance endothelialization of materials. Acta Biomater 6: 35063513.

Donalies M, Cramer M, Ringwald M, Starzinski-Powitz A (1991) Expression of M-cadherin, a member of the cadherin multigene family, correlates with differentiation of skeletal muscle cells. Proc Natl Acad Sci U S A 88: 8024-8028.

Duan C, Ren H, Gao S (2010) Insulin-like growth factors (IGFs), IGF receptors, and IGF-binding proteins: roles in skeletal muscle growth and differentiation. Gen Comp Endocrinol 167: 344-351.

Elliott JT, Woodward JT, Umarji A, Mei Y, Tona A (2007) The effect of surface chemistry on the formation of thin films of native fibrillar collagen. Biomaterials 28: 576-585.

Engler AJ, Griffin MA, Sen S, Bonnemann CG, Sweeney HL, Discher DE (2004) Myotubes differentiate optimally on substrates with tissue-like stiffness: pathological implications for soft or stiff microenvironments. J Cell Biol 166: 877-887.

Engler AJ, Sen S, Sweeney HL, Discher DE (2006) Matrix elasticity directs stem cell lineage specification. Cell 126: 677-689.

Esposito A, Germinario E, Zanin M, Palade PT, Betto R, Danieli-Betto D (2007) Isoform switching in myofibrillar and excitation-contraction coupling proteins contributes to diminished contractile function in regenerating rat soleus muscle. J Appl Physiol 102: 1640-1648.

Ewton DZ, Coolican SA, Mohan S, Chernausek SD, Florini JR (1998) Modulation of insulin-like growth factor actions in L6A1 myoblasts by insulin-like growth factor binding protein (IGFBP)-4 and IGFBP-5: a dual role for IGFBP-5. J Cell Physiol 177: 47-57.

Ferreira JC, Bacurau AV, Evangelista FS, Coelho MA, Oliveira EM, Casarini DE, Krieger JE, Brum PC (2008) The role of local and systemic renin angiotensin system activation in a genetic model of sympathetic hyperactivityinduced heart failure in mice. Am J Physiol Regul Integr Comp Physiol 294: R26-32.
Frangogiannis NG, Mendoza LH, Lindsey ML, Ballantyne CM, Michael LH, Smith CW, Entman ML (2000) IL-10 is induced in the reperfused myocardium and may modulate the reaction to injury. J Immunol 165: 2798-2808.

Gayraud-Morel B, Chretien F, Flamant P, Gomes D, Zammit PS, Tajbakhsh S (2007) A role for the myogenic determination gene Myf5 in adult regenerative myogenesis. Dev Biol 312: 13-28.

Grounds MD (2008) Complexity of extracellular matrix and skeletal muscle regeneration. In: Skeletal Muscle Repair and Regeneration (Schiaffino S, Patridge T, eds), Springer, New York, pp 269-301.

Guan K, Rohwedel J, Wobus AM (1999) Embryonic stem cell differentiation models: cardiogenesis, myogenesis, neurogenesis, epithelial and vascular smooth muscle cell differentiation in vitro. Cytotechnology 30: 211-226.

Hayward R, Nossuli TO, Scalia R, Lefer AM (1997) Cardioprotective effect of interleukin-10 in murine myocardial ischemia-reperfusion. Eur J Pharmacol 334: 157-163.

Kennedy KA, Porter T, Mehta V, Ryan SD, Price F, Peshdary V, Karamboulas C, Savage J, Drysdale TA, Li SC, Bennett SA, Skerjanc IS (2009) Retinoic acid enhances skeletal muscle progenitor formation and bypasses inhibition by bone morphogenetic protein 4 but not dominant negative beta-catenin. BMC Biol 7: 67.

Kimura Y, Tabata Y (2010) Controlled release of stromal-cell-derived factor-1 from gelatin hydrogels enhances angiogenesis. J Biomater Sci 21: 37-51.

Klein D, Hohn HP, Kleff V, Tilki D, Ergun S (2010) Vascular wall-resident stem cells. Histol Histopathol 25: 681-689.

Ko HC, Milthorpe BK, McFarland CD (2007) Engineering thick tissues - the vascularisation problem. Eur Cell Mater 14: 1-18; discussion 18-19.

Koffler J, Kaufman-Francis K, Yulia S, Dana E, Daria AP, Landesberg A, Levenberg S (2011) Improved vascular organization enhances functional integration of engineered skeletal muscle grafts. Proc Natl Acad Sci U S A 108: 14789-14794.

Koike T, Vernon RB, Gooden MD, Sadoun E, Reed MJ (2003) Inhibited angiogenesis in aging: a role for TIMP-2. J Gerontol A Biol Sci Med Sci 58: B798-805.

Kovanen V (2002) Intramuscular extracellular matrix: complex environment of muscle cells. Exerc Sport Sci Rev 30: $20-25$.

Kroehne V, Heschel I, Schugner F, Lasrich D, Bartsch JW, Jockusch H (2008) Use of a novel collagen matrix with oriented pore structure for muscle cell differentiation in cell culture and in grafts. J Cell Mol Med 12: 1640-1648.

Kuang S, Kuroda K, Le Grand F, Rudnicki MA (2007) Asymmetric self-renewal and commitment of satellite stem cells in muscle. Cell 129: 999-1010.

Kuraitis D, Giordano C, Ruel M, Musarò A, Suuronen EJ (2012) Exploiting extracellular matrix-stem cell interactions: A review of natural materials for therapeutic muscle regeneration. Biomaterials 33: 428-443.

Kuraitis D, Hou C, Zhang Y, Vulesevic B, Sofrenovic T, McKee D, Sharif Z, Ruel M, Suuronen EJ (2011a) Ex 
vivo generation of a highly potent population of circulating angiogenic cells using a collagen matrix. J Mol Cell Cardiol 51: 187-197.

Kuraitis D, Zhang P, Zhang Y, Padavan DT, McEwan K, Sofrenovic T, McKee D, Zhang J, Griffith M, Cao X, Musaro A, Ruel M, Suuronen EJ (2011b) A stromal cellderived factor-1 releasing matrix enhances the progenitor cell response and blood vessel growth in ischaemic skeletal muscle. Eur Cell Mater 22: 109-123.

Li Z, Liu HY, Lei QF, Zhang C, Li SN (2011) Improved motor function in dko mice by intravenous transplantation of bone marrow-derived mesenchymal stromal cells. Cytotherapy 13: 69-77.

Limbourg A, Korff T, Napp LC, Schaper W, Drexler H, Limbourg FP (2009) Evaluation of postnatal arteriogenesis and angiogenesis in a mouse model of hind-limb ischemia. Nat Protoc 4: 1737-1746.

Liu Y, Chu A, Chakroun I, Islam U, Blais A (2010) Cooperation between myogenic regulatory factors and SIX family transcription factors is important for myoblast differentiation. Nucleic Acids Res 38: 6857-6871.

Martin TA, Watkins G, Lane J, Jiang WG (2005) Assessing microvessels and angiogenesis in human breast cancer, using VE-cadherin. Histopathology 46: 422-430.

McGeachie JK, Grounds MD (1987) Initiation and duration of muscle precursor replication after mild and severe injury to skeletal muscle of mice. An autoradiographic study. Cell Tissue Res 248: 125-130.

Millon LE, Oates CJ, Wan W (2009) Compression properties of polyvinyl alcohol - bacterial cellulose nanocomposite. J Biomed Mater Res B Appl Biomater 90: 922-929.

Montarras D, Morgan J, Collins C, Relaix F, Zaffran S, Cumano A, Partridge T, Buckingham M (2005) Direct isolation of satellite cells for skeletal muscle regeneration. Science 309: 2064-2067.

Musaro A, Rosenthal N (1999) Maturation of the myogenic program is induced by postmitotic expression of insulin-like growth factor I. Mol Cell Biol 19: 3115-3124.

Nabeshima Y, Hanaoka K, Hayasaka M, Esumi E, Li S, Nonaka I (1993) Myogenin gene disruption results in perinatal lethality because of severe muscle defect. Nature 364: 532-535.

Ning Y, Schuller AG, Bradshaw S, Rotwein P, Ludwig T, Frystyk J, Pintar JE (2006) Diminished growth and enhanced glucose metabolism in triple knockout mice containing mutations of insulin-like growth factor binding protein-3, -4, and -5. Mol Endocrinol 20: 2173-2186.

Parise G, O’Reilly CE, Rudnicki MA(2006) Molecular regulation of myogenic progenitor populations. Appl Physiol Nutr Metab 31: 773-781.

Pelosi L, Giacinti C, Nardis C, Borsellino G, Rizzuto E, Nicoletti C, Wannenes F, Battistini L, Rosenthal N, Molinaro M, Musaro A (2007) Local expression of IGF-1 accelerates muscle regeneration by rapidly modulating inflammatory cytokines and chemokines. FASEB J 21: 1393-1402.

Ridgeway AG, Skerjanc IS (2001) Pax3 is essential for skeletal myogenesis and the expression of Six1 and Eya2. J Biol Chem 276: 19033-19039.
Rossi CA, Pozzobon M, De Coppi P (2010) Advances in musculoskeletal tissue engineering: moving towards therapy. Organogenesis 6: 167-172.

Roy S, Khanna S, Kuhn DE, Rink C, Williams WT, Zweier JL, Sen CK (2006) Transcriptome analysis of the ischemia-reperfused remodeling myocardium: temporal changes in inflammation and extracellular matrix. Physiol Genomics 25: 364-374.

Rudnicki MA, Schnegelsberg PN, Stead RH, Braun T, Arnold HH, Jaenisch R (1993) MyoD or Myf-5 is required for the formation of skeletal muscle. Cell 75: 1351-1359.

Ruvinov E, Leor J, Cohen S (2011) The promotion of myocardial repair by the sequential delivery of IGF-1 and HGF from an injectable alginate biomaterial in a model of acute myocardial infarction. Biomaterials 32: 565-578.

Sabourin LA, Rudnicki MA (2000) The molecular regulation of myogenesis. Clin Genet 57: 16-25.

Saif J, Schwarz TM, Chau DY, Henstock J, Sami P, Leicht SF, Hermann PC, Alcala S, Mulero F, Shakesheff KM, Heeschen C, Aicher A (2010) Combination of injectable multiple growth factor-releasing scaffolds and cell therapy as an advanced modality to enhance tissue neovascularization. Arterioscler Thromb Vasc Biol 30: 1897-1904.

San Antonio JD, Iozzo RV (2006)The two-phase model for angiogenesis regulation by the extracellular matrix. In: Encyclopedia of the Microvasculature (D. Shepro, ed), Elsevier Academic Press, Burlington, pp 127-136.

Savage J, Conley AJ, Blais A, Skerjanc IS (2009) SOX15 and SOX7 differentially regulate the myogenic program in P19 cells. Stem Cells 27: 1231-1243.

Seale P, Ishibashi J, Scime A, Rudnicki MA (2004) Pax7 is necessary and sufficient for the myogenic specification of CD45+:Sca1+ stem cells from injured muscle. PLoS Biol 2: E130.

Seeger FH, Rasper T, Koyanagi M, Fox H, Zeiher AM, Dimmeler S (2009) CXCR4 expression determines functional activity of bone marrow-derived mononuclear cells for therapeutic neovascularization in acute ischemia. Arterioscler Thromb Vasc Biol 29: 1802-1809.

Shi M, Ishikawa M, Kamei N, Nakasa T, Adachi N, Deie M, Asahara T, Ochi M (2009) Acceleration of skeletal muscle regeneration in a rat skeletal muscle injury model by local injection of human peripheral blood-derived CD133-positive cells. Stem Cells 27: 949-960.

Sun D, Martinez CO, Ochoa O, Ruiz-Willhite L, Bonilla JR, Centonze VE, Waite LL, Michalek JE, McManus LM, Shireman PK (2009) Bone marrow-derived cell regulation of skeletal muscle regeneration. FASEB J 23: 382-395.

Suuronen EJ, Kuraitis D, Ruel M (2008) Improving cell engraftment with tissue engineering. Semin Thorac Cardiovasc Surg 20: 110-114.

Suuronen EJ, Zhang P, Kuraitis D, Cao X, Melhuish A, McKee D, Li F, Mesana TG, Veinot JP, Ruel M (2009) An acellular matrix-bound ligand enhances the mobilization, recruitment and therapeutic effects of circulating progenitor cells in a hindlimb ischemia model. FASEB J 23: 1447-1458.

Vignaud A, Hourde C, Medja F, Agbulut O, ButlerBrowne G, Ferry A (2010) Impaired skeletal muscle 
repair after ischemia-reperfusion injury in mice. J Biomed Biotechnol 2010: 724914.

Villalta SA, Rinaldi C, Deng B, Liu G, Fedor B, Tidball JG (2011) Interleukin-10 reduces the pathology of $\mathrm{mdx}$ muscular dystrophy by deactivating M1 macrophages and modulating macrophage phenotype. Hum Mol Genet 20: 790-805.

Wang JS, Liu X, Xue ZY, Alderman L, Tilan JU, Adenika R, Epstein SE, Burnett MS (2011) Effects of aging on time course of neovascularization-related gene expression following acute hindlimb ischemia in mice. Chin Med J (Engl) 124: 1075-1081.

Whitman SC, Rateri DL, Szilvassy SJ, Yokoyama W, Daugherty A (2004) Depletion of natural killer cell function decreases atherosclerosis in low-density lipoprotein receptor null mice. Arterioscler Thromb Vasc Biol 24: 1049-1054.

\section{Discussion with Reviewers}

Reviewer I: Is there no other method for quantifying new muscle cells than centralised nuclei?

Authors: In short, no. Quantification of the number of new myocytes is restricted to histological analysis. Other markers that can be used to identify new, young myocytes are myosin heavy chains, MyoD, myogenin and Myf5, among others. These are less reliable for 2 reasons: (1) non-myocyte muscle precursors can also express these markers; and (2) injured/regenerating myocytes can also re-express these markers under various conditions. A centralised nucleus is the hallmark of a young ( $<1$ month) myocyte and this phenotype does not overlap with other myocyte states. Furthermore, this provides a quantifiable phenotypic analysis of regeneration and is corroborated by our transcription (qPCR), protein (arrays) and functional (treadmill) analyses of regeneration.

Reviewer I: It is interesting that in the previous manuscript regarding the effects of sLex on muscle regeneration (Suuronen et al., 2009, text reference) the proposed mechanism was recruitment of endogenous cells via an increase in SDF 1 release. However, in this study SDF 1 is released reasonably late in the game when compared to the results indicating an increase in CACs in circulation and CXCR4 cells engrafted in the muscle. Is there another factor at work here and if so what would you hypothesise it to be?

Authors: While CXCR4+ cells should be attracted towards sources of SDF-1, SDF-1 is not the only chemoattractant for CACs. Although SDF-1 release was a relatively late factor, sLeX-matrix treatment augmented much greater levels of local VEGF in treated muscle, which could easily explain the mobilisation and engraftment of CACs. We would like to be able to identify "the factor" that induces such changes, but such a conclusion currently eludes us. Realistically, the regenerative changes we observe are likely a combination of many things, in addition to progenitor cell activation, such as reduced impact of ischaemic injury early on (leading to reduced inflammatory responses) and improved mobility later on (leading to overall better health compared to injured/immobile animals).

Reviewer I: It appears that the homing of cells to the ischaemic region is important for stimulating a local response, but not for generating new muscle or vasculature. Is there a way to cut out the middle man and stimulate the local response without having the bone marrow derived cell homing? Are there ways to block the homing from occurring to measure only the local response of the sLex material?

Authors: Although a few studies have shown transdifferentiation of circulating angiogenic cell populations into vascular and/or muscle lineages, the vast majority of studies have failed to show this phenomenon. Paracrine signalling appears to be the most prominent mechanism to facilitate regeneration. This has been shown in studies whereby application of conditioned medium collected from homing cell populations is equally as effective at restoring hind-limb perfusion as transplanting the cell population itself (Di Santo et al., 2009, additional reference). We have not considered blocking cell homing in order to better characterise the effects of the sLeX-matrix. Based on the observed regeneration, the sLeX-matrix is able to stimulate regeneration via cell homing, local and paracrine effects. Since these aspects of regeneration are all connected, and successful regeneration ideally requires contributions from each, blocking one of these parameters may not necessarily reveal the true full local response.

Reviewer II: Why were mESCs used instead of myoblasts and/or c-kit positive cells as this would be more physiologically and clinically relevant? In addition the sLeX matrix provided no advantage over strictly collagen. Did the authors look at changes in other lineages? It may not be specific to myogenic lineages. Possibly, these results cannot lead to any conclusions about the promotion of endogenous regenerative myogenesis. To do so a relevant cell type should be included.

Authors: We understand that an ESC model is not physiologically or clinically relevant; however, the takehome message of this work is highlighted with the ESC study results. We want to stress that this material has an inherent ability to guide pluripotent cells towards a myocytic lineage. Its design is similar to the Engler et al. (2006) paper (text reference), whereby changes in the seeding material led mesenchymal stem cells to adopt more muscle-, nerve- or osteoblast-like phenotypes.

Reviewer III: While the data on functional changes are appreciated, the reporting of the running distance/ speed should have either data or discussion about what an uninjured animal can do. The increase with sLeX is significant, but if it is still only $50 \%$ of a healthy animal then there is quite a way to go. Please report or discuss data from this study or other studies on healthy running distance and speed.

Authors: Unfortunately, age- and strain-matched data using the same exercise protocol are not available to be presented with the current data. Since these three variables 
(age, strain, and variation in the exercise protocol) may affect the performance on a treadmill test, we prefer to not make the comparison. Ultimately, we were able to show that the sLeX-collagen matrix is the only treatment that allows for a significant functional recovery and we identify this phenomenon in the last paragraph by discussing the need for reperfusion in order for muscle regeneration to occur (which appears to only occur with sLeX-collagen matrix).

Reviewer III: While the addition of sLeX resulted in greater mobilisation of CXCR4+ cells it is unclear what role they played in the response. Would you estimate that they were more involved in the neovascularisation observed or the development of nascent muscle fibres? If they were more involved in fibre development, do you anticipate that animals allowed to recover for longer would see further improvement in function as the fibres matured and do you intend to measure this?

Authors: Given that CXCR4 expression confers greater potential for angiogenesis and paracrine secretion (Seeger et al., 2009, text reference) and that neovascularisation precludes muscle regeneration, we believe that the role of the mobilised CXCR4+ cells was primarily to restore perfusion. Therefore, fibre development is dependent upon neovascularisation. In our study, perfusion was restored with sLeX-matrix treatment by 2 weeks, but molecular evidence (cytokines and transcripts) indicate that myogenesis is still on-going at this point. We cannot predict if there will be a greater functional improvement if recovery were to be assessed at a later time point, but we believe that the new fibres would be better developed at such a later time. Future studies will assess this. After the myogenic response has reached its plateau, we would expect to see reversal of the increased molecular marker expression back towards baseline levels and also increased muscle strength when muscles are analysed ex vivo.

Reviewer III: Presumably upon implantation these matrices will eventually be remodelled by the cells in the patient. Do you think there would be any differences in the remodelling response between the collagen $v s$. sLeX matrices that has or could add to the beneficial effects of the treatment?

Authors: Two weeks after their application, physical evidence of the matrices themselves was not apparent. The turn-over time would be highly dependent upon the individual's metabolism and responses, and also the amount of material implanted - an increased bolus would take longer to be turned over. In contexts where turn-over is already completed by the study's termination, any differences in remodelling would be sustained from earlier changes induced by the matrices. While we could not specifically evaluate turn-over of our matrices in vivo, we did demonstrate in vitro that the sLeX-collagen matrix had a superior elastic modulus. Although not fully understood, there is evidence of a relationship between the elastic modulus and the turnover of extracellular matrix proteins in tendons and skeletal muscle (Kjaer, 2004; Birch, 2007, additional references). Therefore, it is conceivable that the observed difference in elastic moduli for the 2 matrices may have been a factor in altering the remodelling response, ultimately resulting in greater functional recovery in sLeXcollagen matrix treated hind-limb muscles.

Reviewer IV: The chemical coupling reaction using a mix of proteins, glycosaminoglycans and two cross-linking agents will lead to a mixture of thousands of polymers. I wonder if the laboratories involved have made attempts to characterise them both, at the chemical as well as at the biological level and compared them to what is found in cell membranes of, for example, endothelial cells.

Authors: We agree that there will be a mixture of polymers present (both major and minor products) with the major product(s) being: (1) a collagen hydrogel containing amide bonds, and (2) a collagen-chondroitin hydrogel. Separation of each polymer is difficult and even if one could separate the polymers, an NMR on every single polymer (both major and minor) would be very time consuming and expensive. If our product had been a small molecule, characterisation would be much easier. Since the materials have not been characterised, it is not possible to say if their characteristics are identical to those of the polymers produced endogenously.

\section{Additional References}

Birch HL (2007) Tendon matrix composition and turnover in relation to functional requirements. Int J Exp Pathol 88: 241-248.

Di Santo S, Yang Z, Wyler von Ballmoos M, Voelzmann J, Diehm N, Baumgartner I, Kalka C (2009) Novel cell-free strategy for therapeutic angiogenesis: in vitro generated conditioned medium can replace progenitor cell transplantation. PloS One 4: e5643.

Kjaer M (2004) Role of extracellular matrix in adaptation of tendon and skeletal muscle to mechanical loading. Physiol Rev 84: 649-698. 